\title{
Ice Growth Measurements From Image Data to Support Ice-Crystal and Mixed-Phase Accretion Testing
}

Peter M. Struk

Glenn Research Center, Cleveland, Ohio

Christopher J. Lynch

Wyle Information Systems, Cleveland, Ohio 


\section{NASA STI Program . . . in Profile}

Since its founding, NASA has been dedicated to the advancement of aeronautics and space science. The NASA Scientific and Technical Information (STI) program plays a key part in helping NASA maintain this important role.

The NASA STI Program operates under the auspices of the Agency Chief Information Officer. It collects, organizes, provides for archiving, and disseminates NASA's STI. The NASA STI program provides access to the NASA Aeronautics and Space Database and its public interface, the NASA Technical Reports Server, thus providing one of the largest collections of aeronautical and space science STI in the world. Results are published in both non-NASA channels and by NASA in the NASA STI Report Series, which includes the following report types:

- TECHNICAL PUBLICATION. Reports of completed research or a major significant phase of research that present the results of NASA programs and include extensive data or theoretical analysis. Includes compilations of significant scientific and technical data and information deemed to be of continuing reference value. NASA counterpart of peer-reviewed formal professional papers but has less stringent limitations on manuscript length and extent of graphic presentations.

- TECHNICAL MEMORANDUM. Scientific and technical findings that are preliminary or of specialized interest, e.g., quick release reports, working papers, and bibliographies that contain minimal annotation. Does not contain extensive analysis.

- CONTRACTOR REPORT. Scientific and technical findings by NASA-sponsored contractors and grantees.
- CONFERENCE PUBLICATION. Collected papers from scientific and technical conferences, symposia, seminars, or other meetings sponsored or cosponsored by NASA.

- SPECIAL PUBLICATION. Scientific, technical, or historical information from NASA programs, projects, and missions, often concerned with subjects having substantial public interest.

- TECHNICAL TRANSLATION. Englishlanguage translations of foreign scientific and technical material pertinent to NASA's mission.

Specialized services also include creating custom thesauri, building customized databases, organizing and publishing research results.

For more information about the NASA STI program, see the following:

- Access the NASA STI program home page at http://www.sti.nasa.gov

- E-mail your question to help@sti.nasa.gov

- Fax your question to the NASA STI Information Desk at 443-757-5803

- Phone the NASA STI Information Desk at 443-757-5802

- Write to: STI Information Desk NASA Center for AeroSpace Information 7115 Standard Drive Hanover, MD 21076-1320 


\section{Ice Growth Measurements From Image Data to Support Ice-Crystal and Mixed-Phase Accretion Testing}

Peter M. Struk

Glenn Research Center, Cleveland, Ohio

Christopher J. Lynch

Wyle Information Systems, Cleveland, Ohio

Prepared for the

Atmospheric and Space Environments Conference

sponsored by the American Institute of Aeronautics and Astronautics

New Orleans, Louisiana, June 25-28, 2012

National Aeronautics and

Space Administration

Glenn Research Center

Cleveland, Ohio 44135 


\section{Acknowledgments}

The authors acknowledge the support for this work by the Atmospheric Environment Safety Technologies (AEST) project under NASA's Aviation Safety Program. The authors thank key team members, Dr. Jen-Ching Tsao, Dr. Mario Vargas, and Dr. Andy Broeren, for discussions and review of the material in this paper. In addition, the authors acknowledge the collaboration between NASA and the NRC as well as key NRC personnel including Dr. Tom Currie, Mr. Dan Fuleki, and Dr. Danny Knezevici. Funding for the NRC work comes from the Federal Aviation Administration and Transport Canada. Special thanks are extended to Mr. Jim MacLeod and Mr. Thomas Bond for their support of the work.

This report contains preliminary findings, subject to revision as analysis proceeds.

Trade names and trademarks are used in this report for identification only. Their usage does not constitute an official endorsement, either expressed or implied, by the National Aeronautics and Space Administration.

Level of Review: This material has been technically reviewed by technical management.

Available from

NASA Center for Aerospace Information 7115 Standard Drive

Hanover, MD 21076-1320
National Technical Information Service 5301 Shawnee Road Alexandria, VA 22312 


\title{
Ice Growth Measurements From Image Data to Support Ice-Crystal and Mixed-Phase Accretion Testing
}

\author{
Peter M. Struk \\ National Aeronautics and Space Administration \\ Glenn Research Center \\ Cleveland, Ohio 44135 \\ Christopher J. Lynch \\ Wyle Information Systems \\ Cleveland, Ohio 44135
}

\begin{abstract}
This paper describes the imaging techniques as well as the analysis methods used to measure the ice thickness and growth rate in support of ice-crystal icing tests performed at the National Research Council of Canada (NRC) Research Altitude Test Facility (RATFac). A detailed description of the camera setup, which involves both still and video cameras, as well as the analysis methods using the NASA Spotlight software, are presented. Two cases, one from two different test entries, showing significant ice growth are analyzed in detail describing the ice thickness and growth rate which is generally linear. Estimates of the bias uncertainty are presented for all measurements. Finally some of the challenges related to the imaging and analysis methods are discussed as well as methods used to overcome them.
\end{abstract}

\section{Nomenclature}

$\begin{array}{ll}\text { FOV } & \text { field of view } \\ G & \text { ice thickness (mm) } \\ G_{\max } & \text { maximum ice thickness }(\mathrm{mm}) \\ G_{\min } & \text { minimum ice thickness }(\mathrm{mm}) \\ G_{p i x} & \text { component of ice thickness normal to imaging plane (pixel) } \\ \mathrm{HD} & \text { high definition } \\ \text { IWCi } & \text { bulk ice water content }\left(\mathrm{g} / \mathrm{m}^{3}\right) \\ \mathrm{LWCi} & \text { bulk liquid water content }\left(\mathrm{g} / \mathrm{m}^{3}\right) \\ l_{a} & \text { physical length of scale in image }(\mathrm{mm}) \\ l_{p} & \text { pixel length of scale } l_{a} \text { in image }(\text { pixels) } \\ l_{p, \text { max }} & \text { maximum possible pixel length of scale } l_{a} \text { in image (pixels) } \\ l_{p, \text { min }} & \text { minimum possible pixel length of scale } l_{a} \text { in image (pixels) } \\ \mathrm{M} & \text { Mach number } \\ m & \text { slope from linear curve fit of ice thickness versus time data (mm/s) } \\ \mathrm{P} & \text { pressure }(\mathrm{kPa}) \\ \text { ROI } & \text { region of interest } \\ S & \text { scale factor }(\mathrm{mm} / \text { pixel) } \\ \text { TAT } & \text { total air temperature }\left({ }^{\circ} \mathrm{C}\right) \\ \mathrm{T}_{\mathrm{WB}} & \text { wet-bulb temperature }\left({ }^{\circ} \mathrm{C}\right) \\ t & \text { time }(\mathrm{s}) \\ \alpha & \text { angle between airfoil model chord and horizontal (degrees) } \\ \beta & \text { angle between imaging plane normal and vertical (degrees) }\end{array}$




\section{Introduction}

Experiments are underway to understand the fundamentals of mixed-phase icing associated with icecrystal ingestion into jet engines. Such icing is being attributed to numerous jet engine power-loss events at higher altitudes (Ref. 1). One such set of experiments (Ref. 2) is being conducted jointly by the National Research Council of Canada (NRC) and the Icing Branch of NASA Glenn Research Center with additional support from the Federal Aviation Administration (FAA). The experiments are being performed in the Research Altitude Test Facility (RATFac) of the National Research Council of Canada, which can create ice-crystal and mixed-phase conditions during wind-tunnel tests in above freezing temperatures and pressures representative of cruise altitudes in jet engines (Ref. 3). Further results from those experiments are presented in another paper of this conference (Ref. 4).

The experiments have gathered numerous still and video image data showing the ice accretion behavior in various conditions. The imaging data was intended for both observations and quantitative measurements. These images represent the only record of the icing behavior as traditional methods of recording ice shapes such as ice tracings and castings were not easily adaptable to this experiment. It is necessary to extract quantitative measurements from the images of the accreted ice shape. Ultimately, it is desired to be able to extract two-dimensional and three-dimensional shapes from the images. As a first step, the ice growth along the leading edge is measured and is the primary topic of this paper. This paper describes the cameras and setup used to generate the images as well as the analysis methods used to measure the ice thickness. The analysis results of some selected cases are presented in this paper. In addition, estimates of the measurement uncertainty are presented. Finally, some of the challenges related to the imaging acquisition and analysis methods are discussed as well as methods used to overcome them.

To date, three test entries have been performed at the RATFac as part of this research effort: (1) November 2010, (2) March 2011, and (3) March and April 2012. A detailed description of the experimental setup for the first two test entries can be found in Struk et al. (Ref. 2) and Currie et al. (Ref. 4), respectively. The testing from the third, and most recent test entry, has yet to be reported but comments related to the imaging will be briefly discussed here. Each test entry has attempted to improve the imaging diagnostics based on observations and lessons learned from the previous test efforts.

\section{Imaging Setup}

Still image and video cameras captured high resolution image data during each test run of the experiments. Figure 1 and Figure 2 show the three primary views used during all of the test entries. The test section had a clear acrylic window on both sides allowing for a backlit image to be captured (Figure 1, left). The backlit view was intended to capture ice-shape profiles as they developed on the airfoil's leading edge. A front perspective view (Figure 1, right) was also imaged allowing a view of both the top and bottom surface of the airfoil. Additionally, there was a long narrow window along the top of the test section through which a camera could image the airfoil from the top-down (Figure 2). The topdown views shown in Figure 2 were adjusted between the test entries to optimize the leading-edge ice growth measurements. There was a trade off in the top view as both the ice growth on the leading edge, as well as the aft extent of the ice, were desired measurements. 

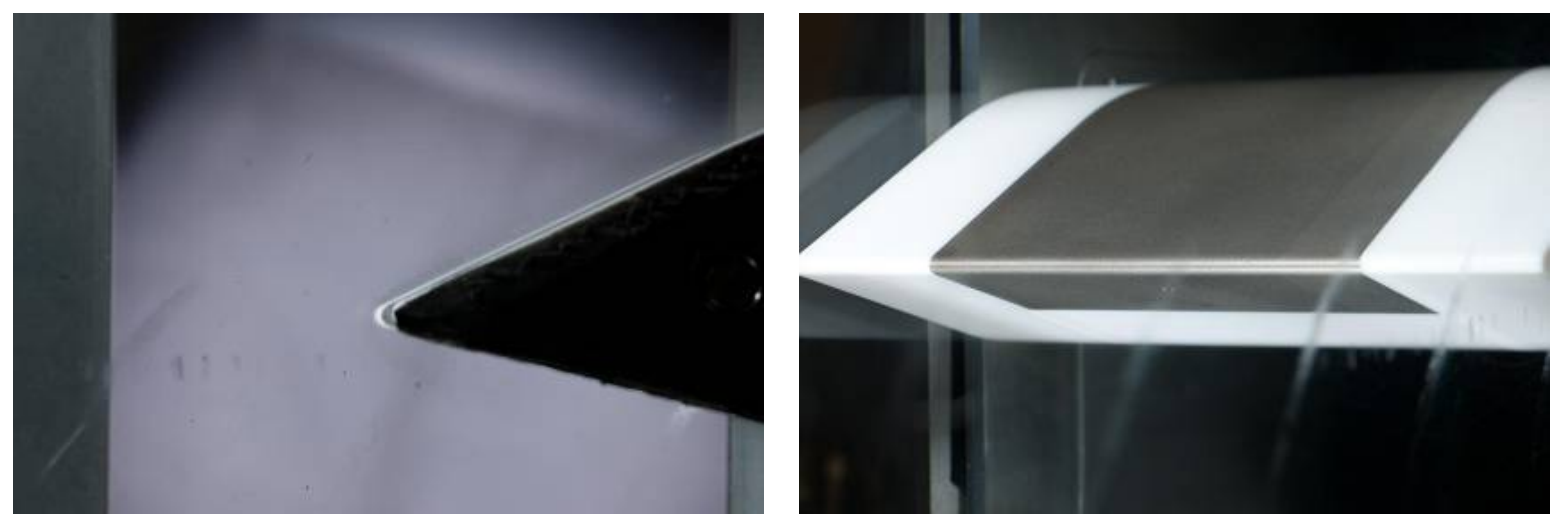

Figure 1.-Two of the three primary imaging views used during all of the test entries: a side backlit view (left) and a front perspective view (right).
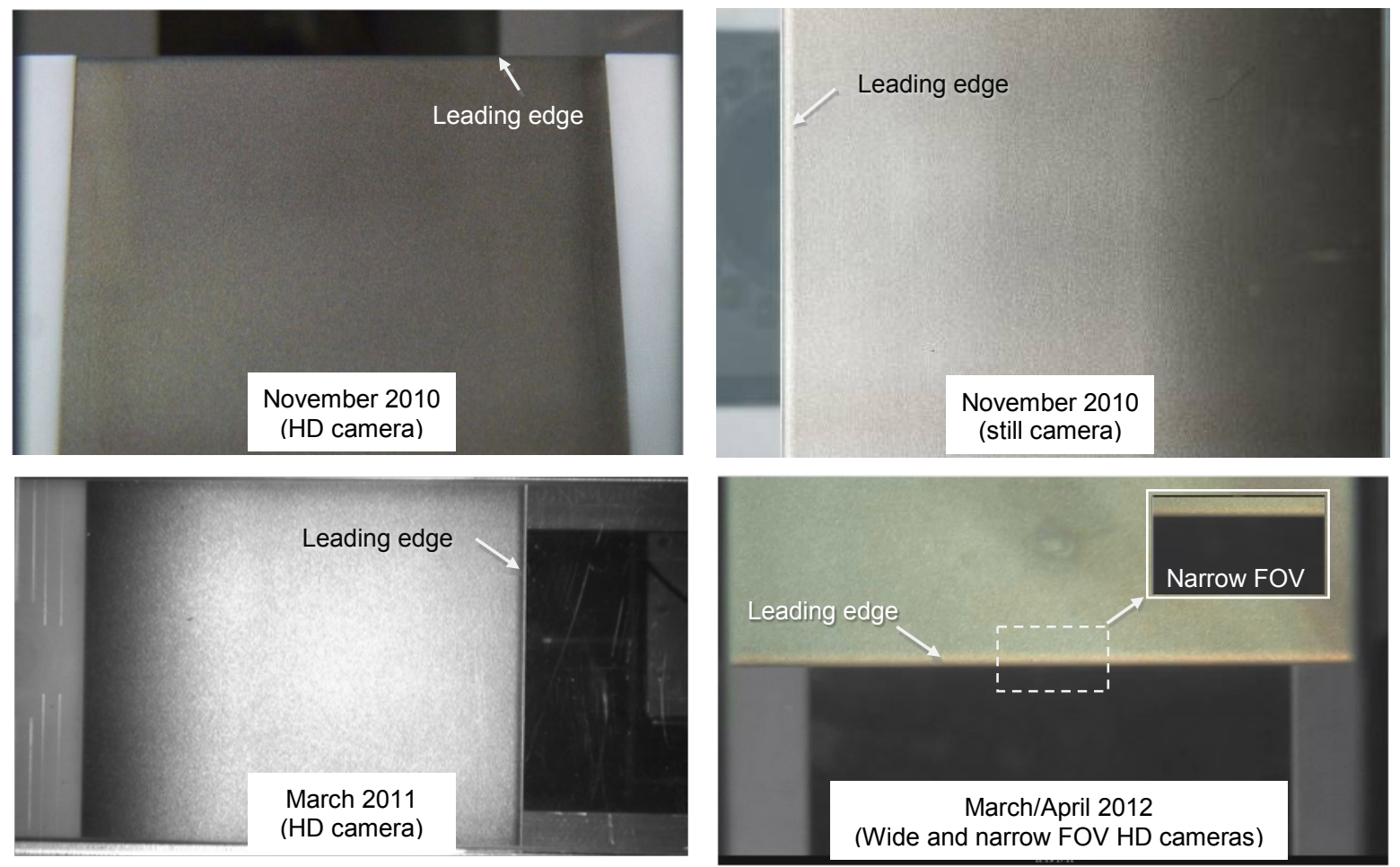

Figure 2.-Imaging views from the top-down cameras used during the various test entries.

The locations of the cameras as setup in the test chamber are shown and labeled in Figure 3 to Figure 4 for the first two test entries, respectively. Still image cameras were used for all three primary views during the first test entry in November 2010 (Figure 3). In addition, a high-definition (HD) video camera provided an additional top-down view allowing real time feedback into the control room. The HD camera was placed in between the end walls of the test rig and viewed the airfoil from the top at a slightly off-normal angle to the viewing window as seen in the upper right image of Figure 3. The video data was not considered primary in the November 2010 test entry and a non-normal viewing angle was the only possible solution due to limited space in the facility. 
During the second test entry (Figure 4), all still cameras were replaced with HD video cameras as the higher time resolution and real-time feedback was preferred over the higher resolution offered by the still cameras. In the most recent test entry, two HD cameras were used in the top-down view: a wide and narrow field-of-view (FOV) camera (see lower right image of Figure 2). Other cameras, including a highspeed camera, were utilized for various purposes during the testing. Only the still and HD video cameras used for the leading-edge ice growth measurements (top-down view) will be discussed further in this paper.

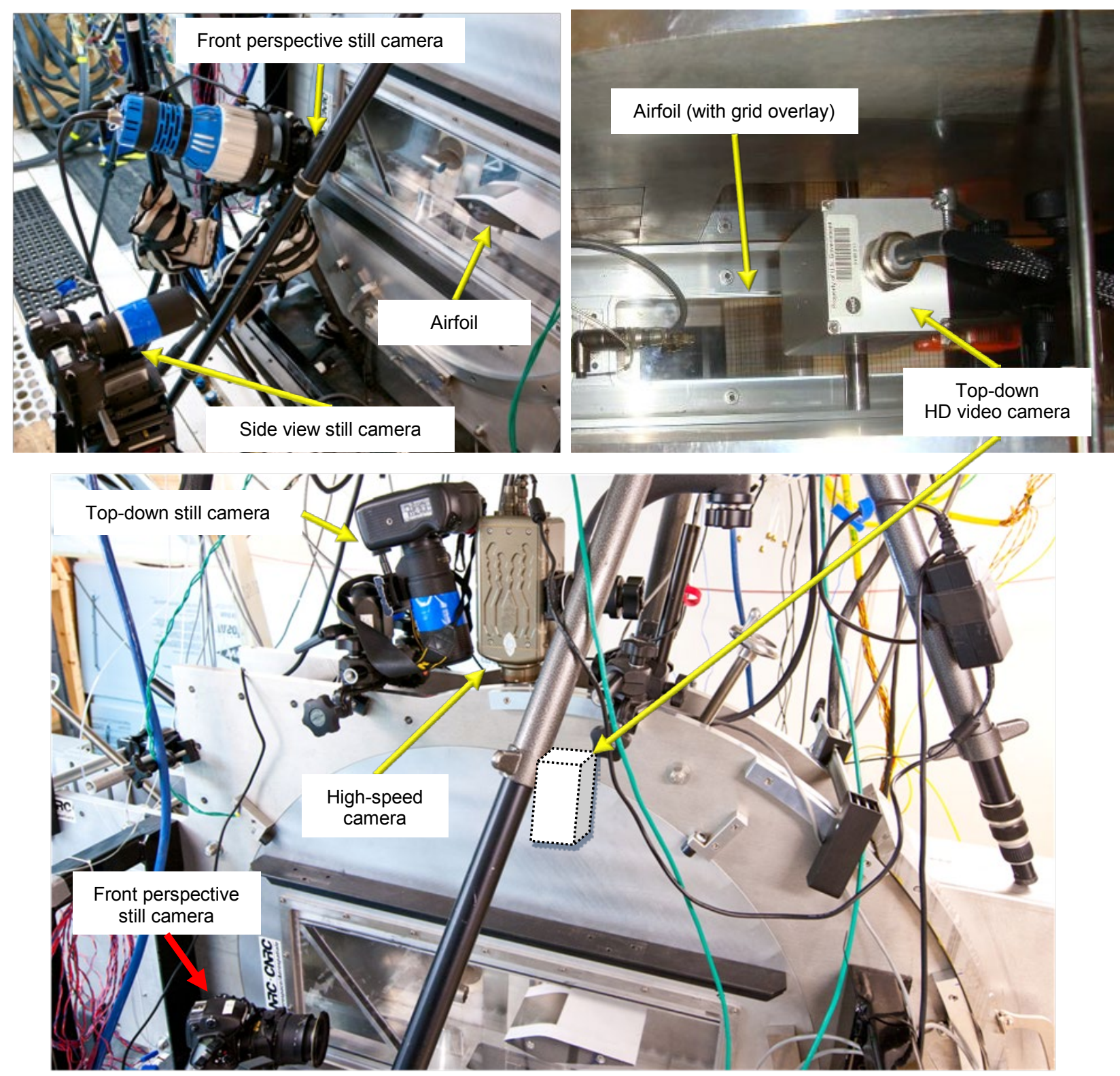

Figure 3.-Position of still and video cameras used during the first test entry (November 2010). Note that the upperright image is looking from the top-down at the test rig. The lower image uses a white hatched rectangular box to show schematically where the HD camera is embedded within the structure of the experimental rig. 

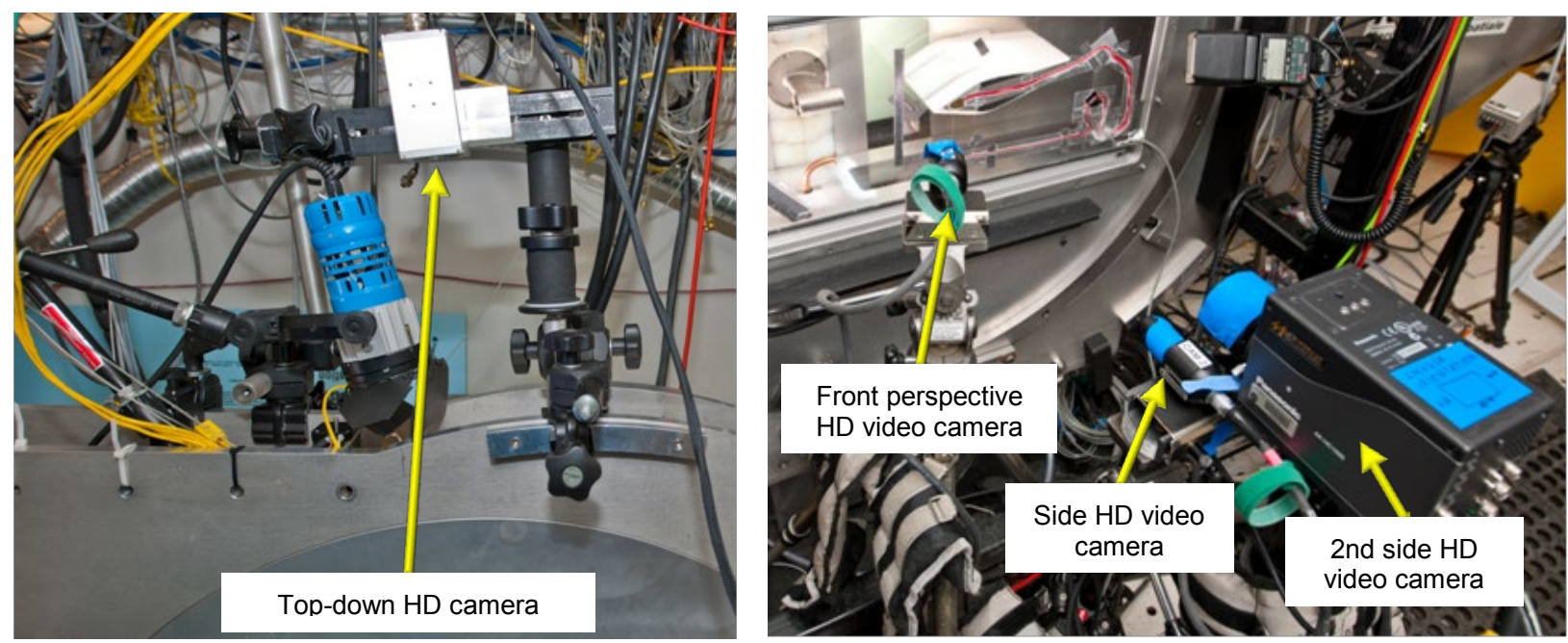

Figure 4.-Positions of video cameras used during the 2nd test entry (March 2011). A second side-view camera was added to see the ice profile at the point of maximum curvature on the airfoil.

\section{Still Cameras-November 2010}

The still cameras (all Nikon model D3X) captured images at a resolution of 6048 by 4032 pixels at a frequency of $0.2 \mathrm{~Hz}$ (although up to $1 \mathrm{~Hz}$ was possible). The number of images captured was preprogrammed and was typically 60 , spanning $300 \mathrm{~s}$. The cameras were manually triggered using a facility signal at the beginning of a test (usually just prior to initiating the ice and/or water spray) and took images continuously for the preprogrammed number. Occasionally, a second set of images was triggered depending on whether the test duration was increased or was not known prior to test initiation. Synchronization of the three still cameras was achieved by opening the shutters of the camera for a specified duration and firing a short flash which illuminated all three camera views. This method was employed as the mechanical shutters on the cameras were difficult to precisely synchronize under continually illuminated conditions. Synchronization between the still cameras and the facility data was achieved by recording the start trigger for the cameras as a facility parameter. Additionally, the bright flashes were visible in the video record, either in a single or two consecutive video frames, which allowed correlation of the video data and still images to within one frame, or $\pm 0.0167 \mathrm{~s}$.

\section{HD Video Cameras}

The top view HD video camera (Sony FCB-H11) produced images at resolutions of 1280 by 720 pixels at a rate of $59.94 \mathrm{~Hz}$ (i.e., described as $720 \mathrm{P}$ or progressive scan in the imaging industry). The flash from the still camera system saturated the HD camera image for a frame or two, thereby leaving a marker in the video data which allowed later synchronization with the still cameras. During later tests when the still cameras were removed, only a single flash was used as a marker in the video data which would occur simultaneously with the initiation of an ice and/or water spray. During the March 2011 testing and thereafter, the flash was triggered anytime when the ice flow or water flow was turned on. The flash was observed to go off almost immediately when the water flow was turned on.

However, a delay of a few seconds was observed between when the ice was first observed striking the model and the corresponding flash. The RATFac operators explained this behavior as a result of triggering the camera flash to a facility signal corresponding to when positive ice flow has been established (i.e., not when the ice was commanded to start).

During the March 2011 test entry, the perspective and side-view still cameras were replaced with different models of HD view cameras (Iconix, model HD-RH1). Later during this test entry, a second side-view HD camera (Panasonic, model AK-HC1500) was added (see Figure 4) to see the ice profile at 
the point of maximum curvature on the airfoil. In the March 2011 tests, the top view HD camera was positioned more normal to the chord of the airfoil (similar to the location of the same still camera view in November 2010). In addition, the top-view camera were zoomed out slightly more for the March 2011 tests allowing a larger field of view (FOV) due to anticipated larger ice growths (in the November tests, some of the ice growths grew out of the FOV).

In the third test entry, March and April 2012, two Sony FCB-H11 HD cameras were used to image the ice growth on the leading edge: a wide FOV and a new narrow FOV camera which allowed for more resolution for smaller ice growths (see lower right image of Figure 2). Smaller ice growths were desirable from a scientific perspective as smaller ice accretions would influence the flow field around an airfoil less thus allowing better interpretation of the icing results.

\section{Image Analysis}

The leading-edge ice thickness as a function of time was measured from the top-down camera views. The HD video camera data were analyzed for all available cases as it offered more time resolution $(\sim 60 \mathrm{~Hz})$ compared with the still cameras $(0.2 \mathrm{~Hz})$ at the expense of resolution. However, the resolution of the HD video was adequate to measure leading-edge ice thicknesses for cases where the thickness of the ice grew to thicknesses on the order of $1 \mathrm{~mm}$ or greater. For cases in which the ice growth was substantial, the video camera FOV was adjustable in real time (via a remote zoom out feature) allowing the entire ice growth to be captured. However, the change in the FOV required adjusting the scale factor to convert from pixels to a physical dimension each time the image zoom was changed.

The leading-edge ice thickness measurement was made at midspan using the Spotlight software developed by NASA (Ref. 5). The thickness of ice in pixels, $G_{p i x}$, is the measured distance between the leading edge of the airfoil and the visible edge of the ice (Figure 5). This measured thickness can be less than the thickness normal to the leading edge of the airfoil due to the orientation of the camera relative to the airfoil. In addition, the airfoil itself can be at an angle relative to the horizontal, which is denoted as $\alpha$ in Figure 5. To obtain the ice thickness, G, normal to the leading edge requires a trigonometric correction of the measured value of $G_{p i x}$ as well as a conversion to physical units using a scale factor, $S$, as shown in Equation (1).

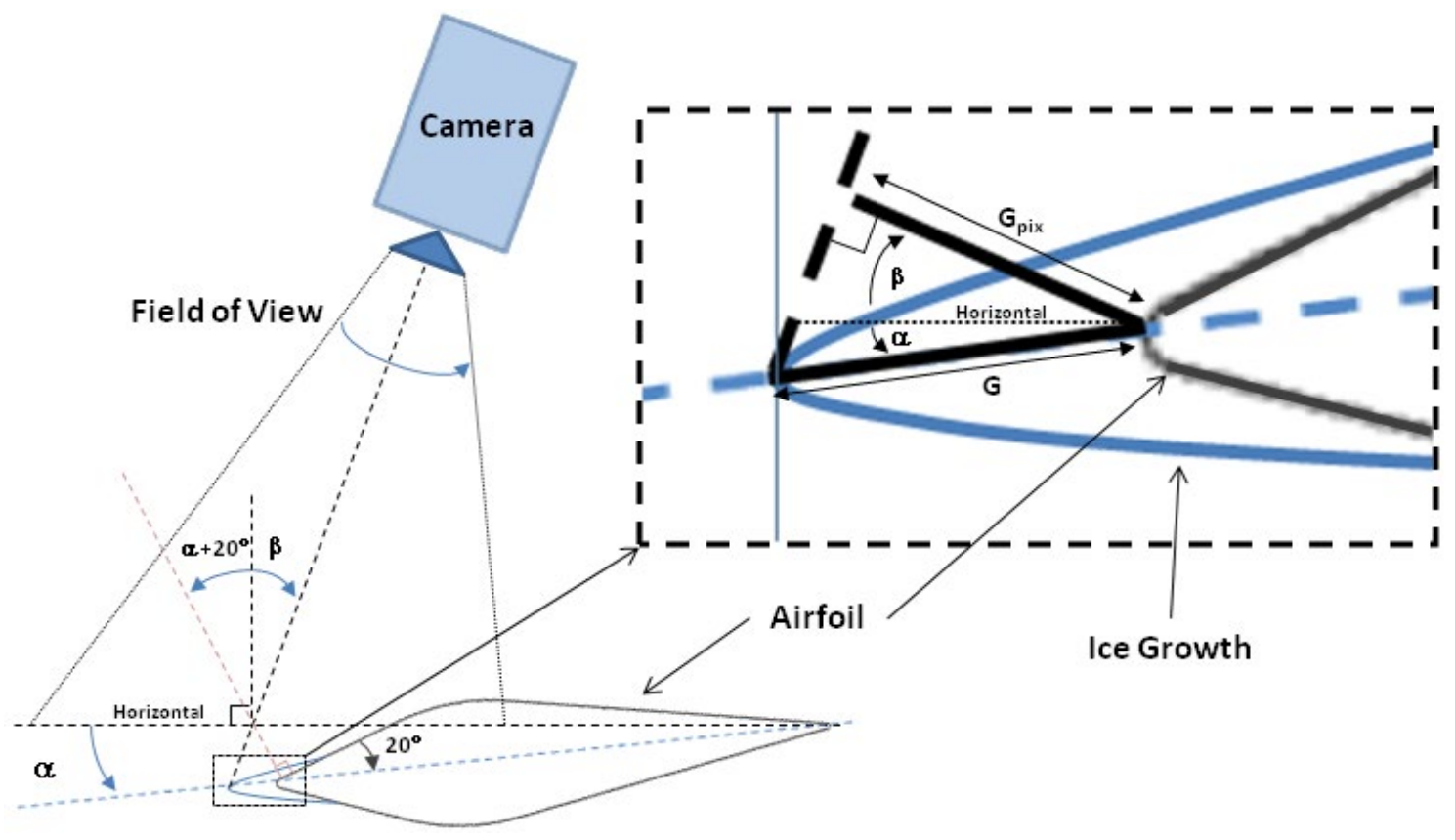

Figure 5.-Orientation of the camera relative to airfoil. 


$$
G=\frac{G_{p i x}}{S \cos (\alpha+\beta)}
$$

\section{Measurement Process}

The measurement process of the ice thickness had three primary steps.

\section{Region of Interest (ROI) Definition}

The first step of the measurement process is to define the region of interest (ROI) as shown in Figure 6. Initially, a single ROI (red rectangle) was defined which was 11 pixels wide in the spanwise direction, centered at midspan, and 200 pixels long in the chordwise direction. The ROI is the region where the software conducted its analysis and was inclusive of the leading edge and/or ice edge. The measurement of the ice thickness was taken at the vertical midpoint of the 11 pixel wide ROI using the "constrain to line" option in Spotlight. The ROI was given a thickness greater than 1 pixel spanwise so that the edge of the detected ice could be seen graphically by the data analyst. An 11 pixel wide ROI worked well. This graphical feedback was important to make sure that the analysis was tracking the edge of the ice properly. Figure 7 shows an example of a single ROI analysis used for a relatively uniform ice growth along the spanwise direction of the airfoil.

Occasionally, cases had spanwise nonuniform ice growth or image obscuration which required further steps to analyze. An effective method to eliminate noise due to image obscuration was to define multiple ROIs at various spanwise locations. The multiple ROIs could then be filtered by removing outlying points to eliminate the noise - this method is effective when the ice thickness is relatively uniform. However, there were several cases where ice did not uniformly grow and one example is shown in Figure 8 . The multiple ROIs could be used in these cases to determine the ice growth at a particular spanwise location and/or be used to determine the minimum and maximum values of ice growth.

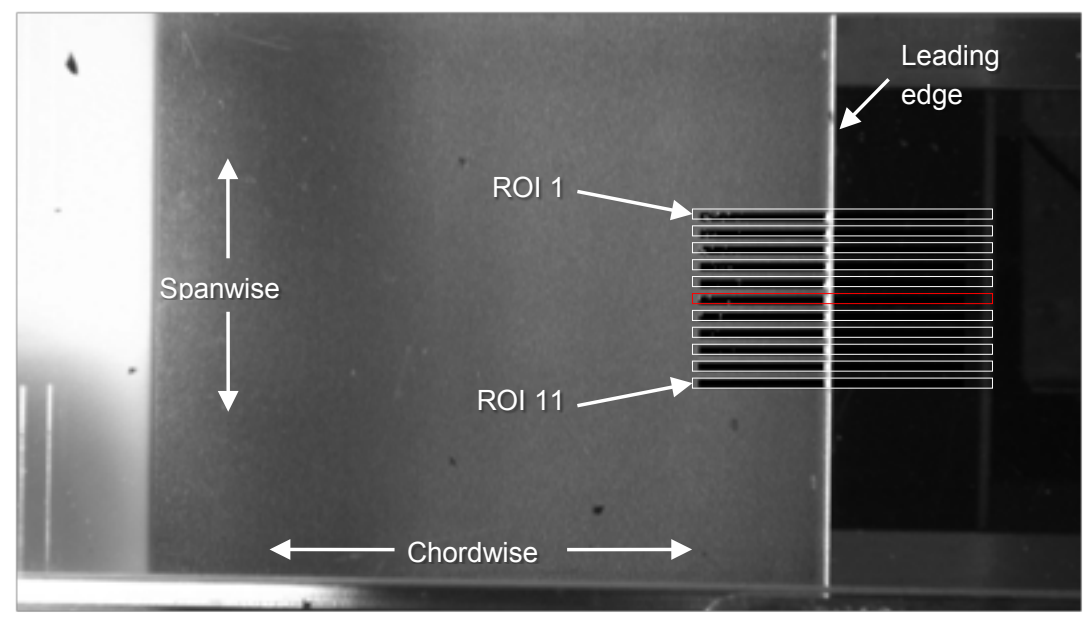

Figure 6.--Region of Interest (ROI) definition shown on an ice-free airfoil. The red rectangle shows the initial $\mathrm{ROI}$ used in the analysis. Later, additional ROls were added for cases where the ice-growth was not uniform across the airfoil or for cases where ice or water contamination affected the analysis. 


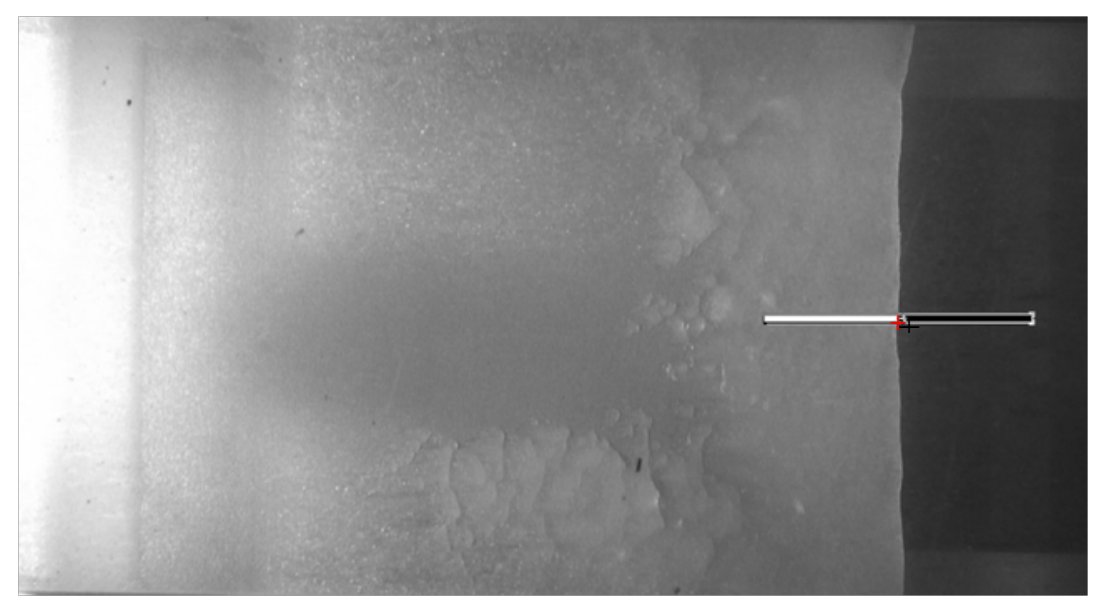

Figure 7.-An example of a single ROI analysis used for a relatively uniform and symmetric ice growth along the spanwise direction of the airfoil. The edge detection begins from the rightmost portion of the ROI and works towards the leading edge of the ice.

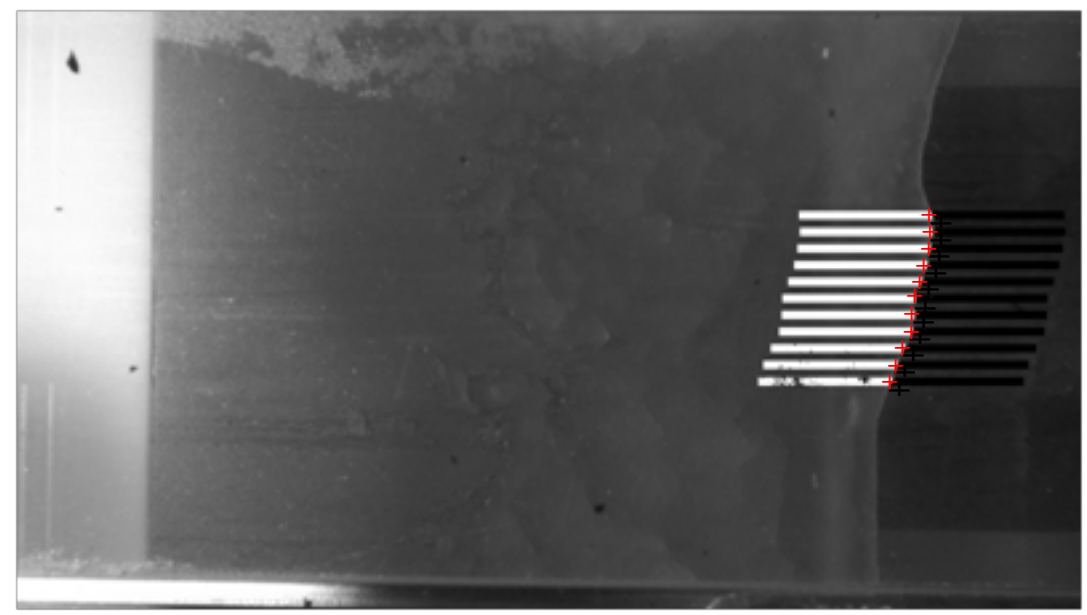

Figure 8.-An example frame from a multiple ROI analysis used for cases where the ice-growth was not uniform across the airfoil or for cases where ice or water contamination affected the analysis.

Another method to analyze cases where image obscuration caused analysis difficulties involved analyzing the ice shape beginning from the airfoil leading edge and working outward toward the edge of the ice (Figure 9). This method required the definition of two addition ROIs: a masking ROI and contrast adjustment ROI. The masking ROI created a uniform white grey level across the airfoil so that the software did not detect local dark spots as an edge. The contrast enhancement ROI is discussed in the section below. This method of looking for the ice edge outward from the leading edge was especially effective in cases where there was image obscuration due to ice or water on the window. Flowing ice or water would often be observed on the top window and be mistaken as the edge of the ice by the analysis algorithm. This was especially the case when the software began the detection algorithm from the right of the ROI, which was the direction from which the flow originated, as was the case in Figure 7 and Figure 8.

\section{Edge Detection - Definition of Threshold Grey Level}

The second step was to identify a pixel grey level which best defined the edge of the ice. The grey levels ranged from 0 to 255 (dark to light) for the 8-bit images provided by the cameras. Values above a 
given grey level were considered ice while values below were considered background. Somewhere between these values is a "threshold" grey level which defined the edge to the ice. This threshold was determined visually and varied for each test due to differences in lighting, cloud reflections which changed at different water concentrations, etc. Once the threshold was defined, the Spotlight software determines the location along a line where this grey level first occurs. As discussed in step 1 above, the actual measurement was constrained to a line at the spanwise midpoint of the ROI. For the case shown in Figure 7 and Figure 8, the software began looking for the edge along that line from the right hand side of the ROI until it detected the first occurrence of the threshold grey level. For the case shown in Figure 9, the edge detection began at the leading edge and worked outward toward the edge of the ice. For this case, the software used an inverse logic for edge detection such that the first occurrence of the threshold grey level from high to low defined that edge. A red cross is shown in the figures which correspond to the location of the leading-edge ice thickness measurement.

Although the grey level of the background varied during a given run, a single value was identified for each run by examining such profiles at various times during a test (early, midway, and near the end). The ability to select a single grey level which worked for an entire test was due primarily to the "Linear Contrast Stretch" operation available in the software. This operation linearly re-maps the range of grey levels in a given ROI to a full grey level range from 0 to 255. This was done to account for the various brightness levels encountered during a typical test run. For instance, the average grey level of the image increased when the cloud spray was turned on due to reflections from ice crystals. The contrast equalization allowed a single threshold grey level to represent the edge of the ice for the entire test duration for most of the test cases. However, select cases required more than a single threshold value to track properly especially for cases where the contrast in the image was poor. Furthermore, the selection of the ROI was important to ensure that sufficient dark and bright pixels were available to ensure good contrast overall. For images affected by ice and water contamination on the window, a larger contrast adjustment ROI (Figure 9) often helped since the contamination was typically localized and would offer poor contrast in only a small area.

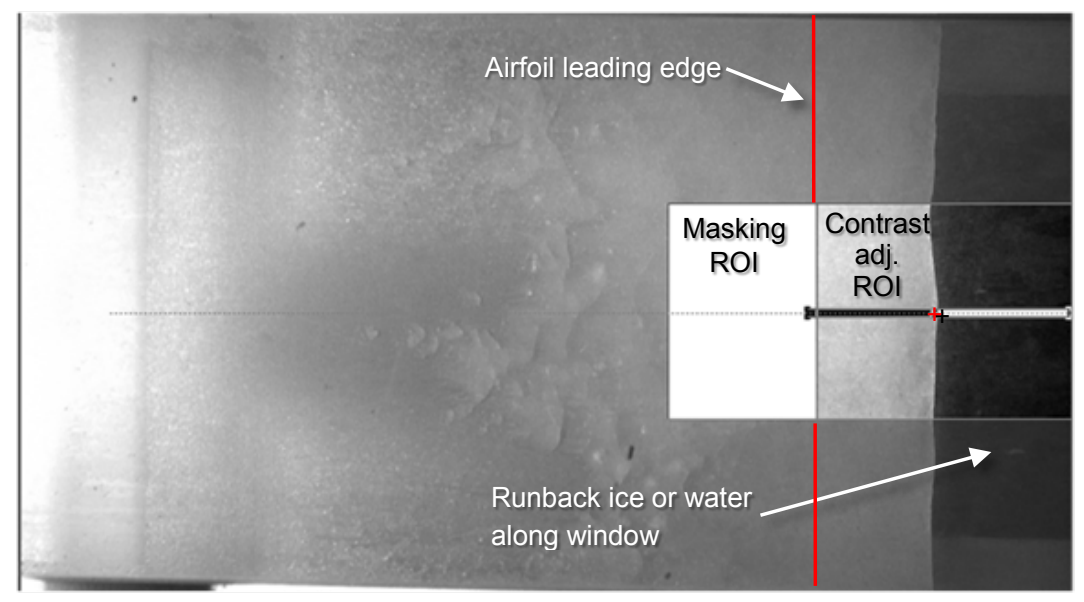

Figure 9.-An example frame from a more complex analysis method where the ice edge detection algorithm begins at the airfoil leading edge and works outward. This method was effective for cases where ice or water on the top window could falsely be detected as the ice edge if started from the right. This method required the definition of two addition ROls: a masking $\mathrm{ROI}$ and contrast adjustment ROI. 


\section{Automated Analysis}

Once the ROIs, threshold grey level (and any processing) are completed, the Spotlight software could continue the measurement from frame to frame automatically. For a $180 \mathrm{~s}$ test there would be 10,800 frames! If the software failed to detect an edge then the analysis would stop and require user interaction to restart. Although the analysis was automated, it was important for the analyst to graphically watch the analysis proceed to ensure that the edge was being properly detected.

Occasionally, ice would be observed along the top window of the test section. This ice would obscure the edge of the ice leading to an erroneous measurement. Due to the large number of data points, these erroneous measurements were typically left in the data set as they did not affect the results. However, if the ice obscuration became too great then a method shown in Figure 9 was tried. In some cases, the analysis was only possible manually as the edge of the ice was still discernible to the human eye but difficult to analyze via a computer algorithm.

\section{Image to Physical Size Scaling}

To convert from image units (pixels), $l_{p}$, to a physical dimension, a known physical length, $l_{a}$, was required in the image. These lengths came from either a known dimension in the image or by placing a scale somewhere in the image. The ratio of $l_{p}$ to $l_{a}$ is defined as the scale factor, $S$, as shown in Equation (2):

$$
S=\frac{l_{p}}{l_{a}}
$$

For the November 2010 data, the width of the metal cover (Figure 10) was a known physical dimension and was measured to be $75.91 \pm 0.05 \mathrm{~mm}$. The measurements were made at various chordwise positions using a caliper where the uncertainty reflects both the chordwise variation and accuracy of caliper. However, the length of the scale in pixels, $l_{p}$, for this width decreased from the bottom to the top of the image due to a perspective effect caused by the camera's imaging plane not being normal to the plane of the metal cover. For the November 2010 data, the angle between the imaging plane and airfoil cover was estimated to be roughly $36^{\circ}\left(\alpha=6^{\circ}, \beta \cong 10^{\circ}\right.$ yielding $6^{\circ}+10^{\circ}+20^{\circ}$ as defined in Figure 5). Unfortunately, the angle $\beta$ was not recorded during the testing and post image inspection could only limit that angle to be between $0^{\circ}$ and $20^{\circ}$ (i.e., $\beta=10^{\circ} \pm 10^{\circ}$ ) for the November 2010 setup. The video data was not considered primary in the November 2010 test entry and a large non-normal viewing angle was required due to limited space to position the camera in the facility.

Due to the perspective effect, a scale factor needed to be determined that was at an appropriate distance from the camera to the ice growth. Since both the airfoil cover and ice growth taper away from the camera at difference angles $\left(\alpha+\beta+20^{\circ}\right.$ and $\alpha+\beta$, respectively), the precise scale factor is difficult to determine. To estimate this scale factor, two lines were created, A and B (see Figure 10), which mathematically extended the edges of the metal cover to the edge of the ice thickness (see blue rectangle representing an imaginary ice thickness of 136 pixels in Figure 10). The distance between lines A and B, parallel to the leading edge of the airfoil at half of the ice thickness was used to calculate $\mathrm{S}$. This was believed to be a reasonable approximation to the scale factor since the plane in which the ice growth thickness, $G$, tapers away from the imaging plane at an angle of $\alpha+\beta$ which is approximately half of the taper angle of the airfoil cover away from the imaging plane $\alpha+\beta+20^{\circ}$. For the example in Figure 10, $S=13.003 \pm 0.093$ pixels $/ \mathrm{mm}$ where the uncertainty estimate accounts for the possible variation in $l_{p}$ from some $l_{p, \min }$ to $l_{p, \max }$ and will be described in a later section. Although this scale was measured horizontally, the same scale factor was applied to measurements of ice thickness in the vertical direction. This was justified because the pixels of the video camera are square avoiding any complications associated with non-square pixels. 


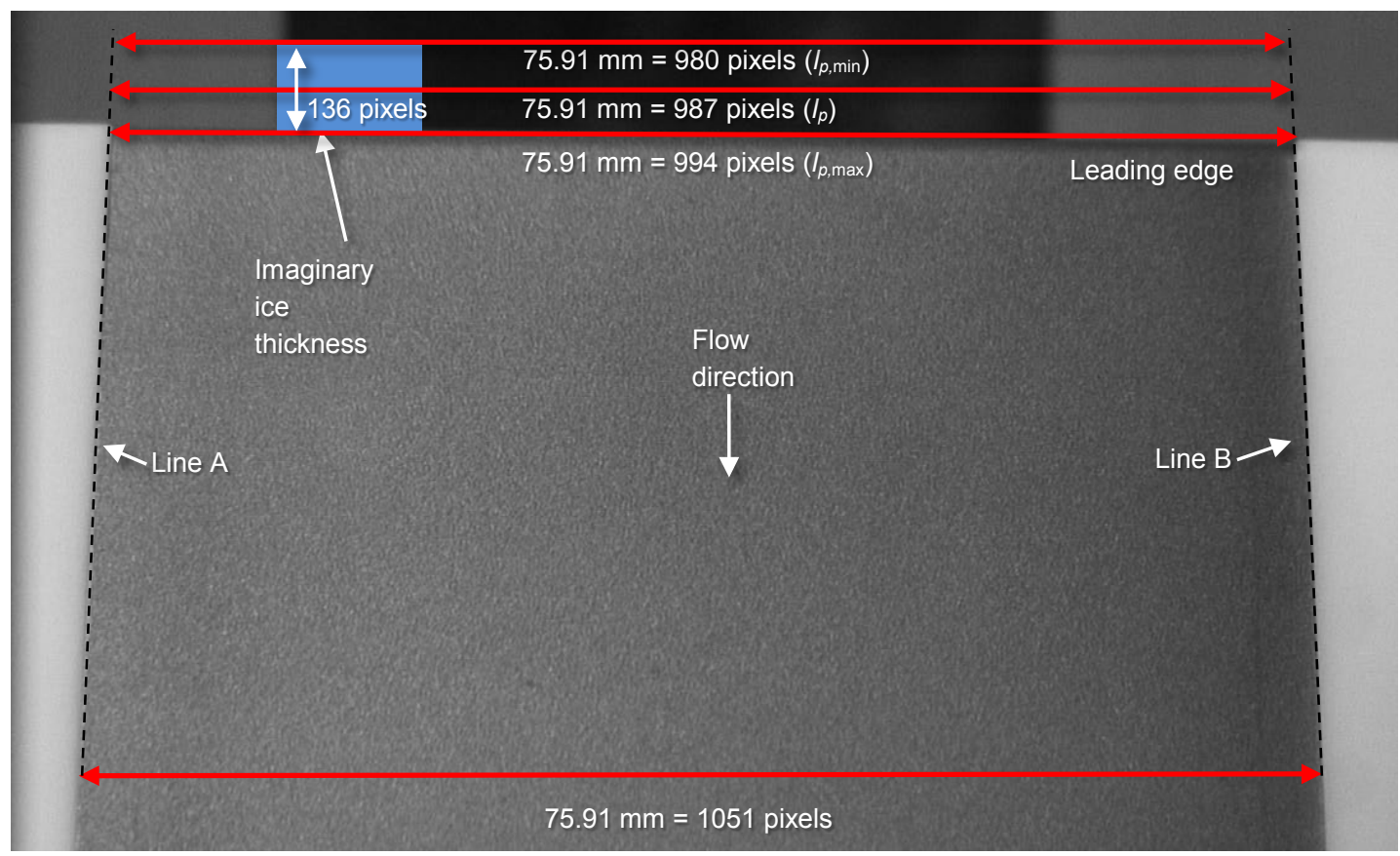

Figure 10.- Scale factor determination using the width of the metal airfoil insert measured to be $75.91 \pm 0.05 \mathrm{~mm}$. The scale factor was calculated for each run. This example is from run 144 .

For the video data beginning in March 2011, a grid was overlaid onto the airfoil and imaged using the cameras (Figure 11). This allowed a physical dimension to be measured in both the chordwise (horizontal) and spanwise (vertical) direction. The grid was printed onto a transparency with a square pattern of $5 \mathrm{~mm}$ in length and width. However, direct measurements in the horizontal direction (as oriented in Figure 11) using a precision scale (i.e., ruler) showed that 43 squares corresponded to $220.0 \mathrm{~mm}$ with a precision of $0.2 \mathrm{~mm}$. Therefore, each grid corresponds to $5.12 \pm 0.01 \mathrm{~mm}$ where the uncertainty was estimated at $0.4 \mathrm{~mm}(0.2 \mathrm{~mm}$ for each side of the measured line $)$ over 43 squares. This grid spacing was verified by a measurement with the same precision scale in the vertical direction which measured a distance of $123 \mathrm{~mm}$ across 24 marks.

During the March 2011 testing, the airfoil was mounted at an angle of attack of $6^{\circ}$ (i.e., $\alpha$ in Figure 5) and the camera was aligned to be normal to the chord of the airfoil although this was not precisely verified during the experiment. Later measurements from photo documentation indicated that the camera imaging plane was aligned at $\beta \cong-6^{\circ}$ as defined in Figure 5. Therefore, there is minimal trigonometric correction of the measured leading edge thickness, $G_{p i x}$, when $\alpha+\beta$ equals $0^{\circ}$ as can be seen by examining Equation (1). However, there is uncertainty in this angle since the photo was at a slightly off angle and was made relative to a horizontal component on the test rig. Therefore, the uncertainty for $\beta$ is estimated to be $\pm 3^{\circ}$ or half the desired angle but is considerably less than the uncertainty estimated for the November 2010 data.

Figure 12 has plots of the grid-element widths and heights, measured using the Spotlight software, along various spanwise and chordwise directions on the airfoil. The middle plot (red symbols) shows the chordwise variation in grid-element width at midspan. As a reference to the middle plot, the airfoil contour is shown in the top plot of Figure 12 to depict that the airfoil surface tapers away from the imaging plane at an angle of $\sim 20^{\circ}\left(\alpha+\beta+20^{\circ}\right.$ as defined in Figure 5). Starting at grid number 1, near the left most portion of the image, the grid-element widths are $\sim 50$ pixels per division in the chordwise direction. The measured grid width decreases to roughly 46 pixels per division at grid 19 which is near the leading edge. 


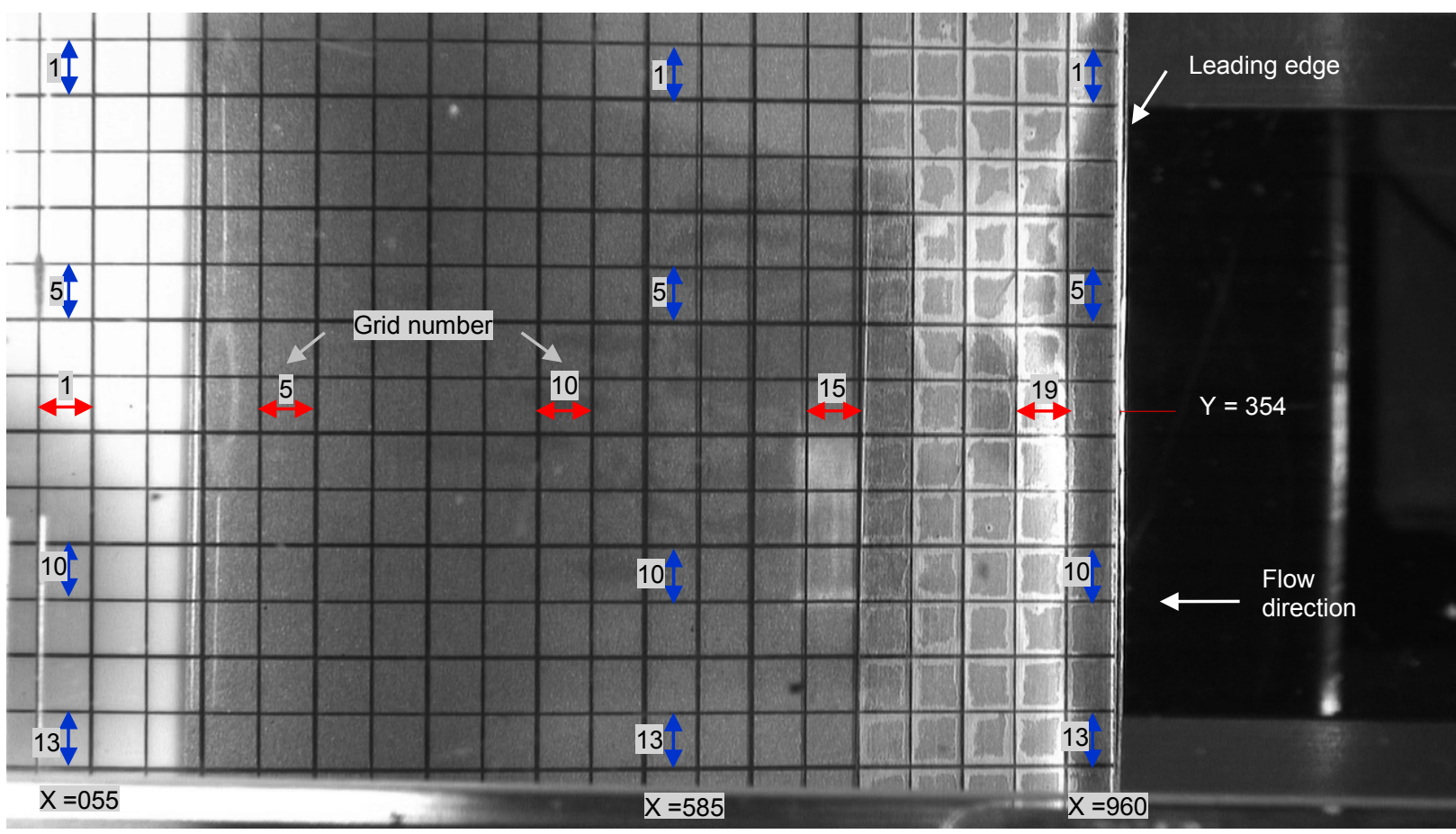

Figure 11.-An example image (from March 8, 2011) used to determine scale factor using an overlaid grid pattern. Each grid square is approximately $5.12 \pm 0.01 \mathrm{~mm}$ in length and width. The numbered grids correspond to the grid widths and heights shown in Figure 12.
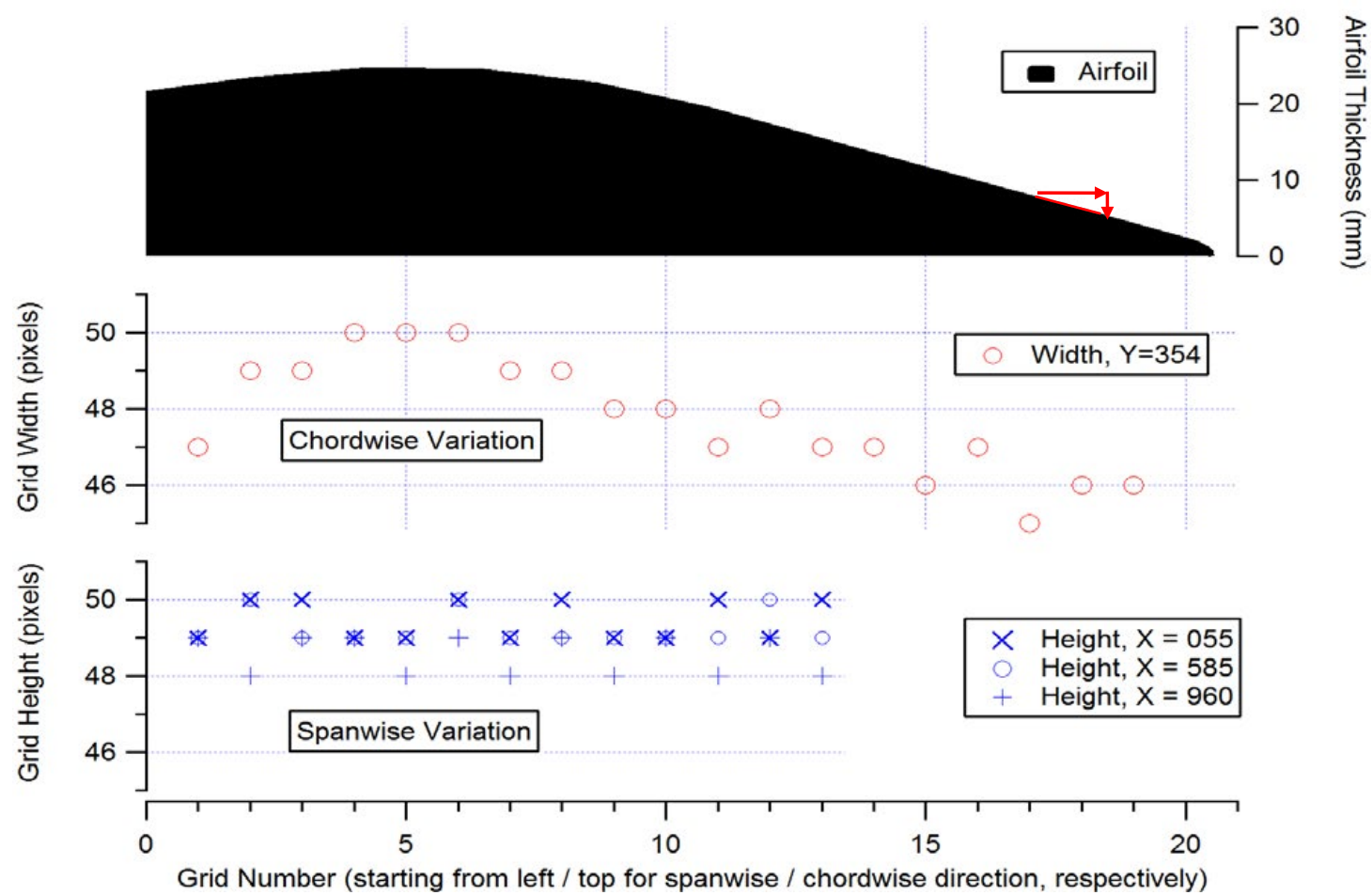

Figure 12.-Grid width and height as a function of position on the airfoil as shown in Figure 11. The figure also shows the contour of the airfoil which helps to visualize a small angular effect caused by the airfoil surface tapering away from the imaging plane. 
The lower plot (blue symbols) in Figure 12 shows the spanwise variation of grid-element height at various chord locations. A quick inspection of the heights suggests a relatively uniform spacing (49 \pm 1 pixels) at all positions. However, a closer inspection shows that the grid spacing between locations $\mathrm{X}=055$ and 960 in Figure 11 actually changes by 12 pixels. This can be seen by summing all the grid heights spanwise which results in 643 and 631 pixels for $X=055$ and 960, respectively. This suggests that a perspective effect is still present in these images although not as severe as in the November 2010 tests (Figure 10).

For the March 2011 tests, the scale factor used was that nearest the leading edge since this was in the same plane as the ice growth. For the data in Figure 12, the grid spacing used was the total height of the 13 visible grids in the spanwise direction at $\mathrm{X}=960$. This corresponded to $l_{p}=631$ pixels with an uncertainty of \pm 2 pixels. In physical units, this distance corresponds to $l_{a}=66.56 \pm 0.13 \mathrm{~mm}$ (13 times $5.12 \pm 0.01$ for each grid). Substituting these values into Equation (2) yields $S=9.480 \pm 0.035$ pixels $/ \mathrm{mm}$. The uncertainty in the scale factor as well as the uncertainty in the overall measured ice thickness is discussed in the next section. Again, the scale factor $S$ varied from day-to-day due to magnification changes but were calculated similarly.

\section{Uncertainty Estimate}

Equation (1) is used to calculate the leading edge ice thickness, $G$, where $G_{p i x}$ is the ice thickness measured in pixels, and $\mathrm{S}$ is the scale factor used to convert pixels to a physical dimension. The angles, $\alpha$ and $\beta$, have been previously defined in Figure 5. It is important to understand the uncertainty in each of the measured parameters $\left(G_{p i x}, \mathrm{~S}, \alpha, \beta\right)$ and how these uncertainties affect the overall calculation of ice thickness. In this paper, the uncertainty of these parameters reflects the measurement bias or systematic error and how those errors affect the overall measurement. The reported uncertainty does not account for the random error associated with possible run-to-run variations of the growth rate under the same prescribed environmental conditions.

Taking the partial derivative of Equation (1) with respect to each of the parameter yields the sensitivity of that equation to variation in that parameter as shown in Equations (3) to (5). Multiplying the partial derivative expressions (i.e., the sensitivity coefficients) by the estimated uncertainty of each parameter provides a measure of the ice thickness variation due to variation of that parameter. Combining these uncertainties using a root-sum-square method (Ref. 6), we can get an expression, shown as Equation (6), for the uncertainty estimate in the reported ice thickness where the differential operators (i.e., $d G_{p i x}, d S$, $d \alpha, d \beta$ ) are the estimated uncertainties for the parameters in the equation. These uncertainty estimates for each parameter should be reported with the same level of confidence to ensure that the overall uncertainty estimate is meaningful. The first grouping on the right hand side of Equation (6) represents the uncertainty associated with the resolution of the measurement. However, there is also uncertainty in the scale factor, $S$, as well as the view angles, $\alpha$ and $\beta$, expressed by the second through fourth grouping of variables on the right hand side of Equation (6).

$$
\begin{gathered}
\frac{\partial G}{\partial G_{p i x}}=\frac{1}{S \cdot \cos (\alpha+\beta)} \\
\frac{\partial G}{\partial S}=\frac{-t_{p i x}}{S^{2} \cdot \cos (\alpha+\beta)} \\
\frac{\partial G}{\partial \alpha}=\frac{\partial G}{\partial \beta}=\frac{G_{p i x}}{S} \sec (\alpha+\beta) \cdot \tan (\alpha+\beta)
\end{gathered}
$$




$$
d G=\left(\left[\frac{\partial G}{\partial G_{p i x}} d G_{p i x}\right]^{2}+\left[\frac{\partial G}{\partial S} d S\right]^{2}+\left[\frac{\partial G}{\partial \alpha} d \alpha\right]^{2}+\left[\frac{\partial G}{\partial \beta} d \beta\right]^{2}\right)^{1 / 2}
$$

As a worst case, we can estimate $d G_{p i x}$ as \pm 2 pixels, one pixel for each side of the line we are measuring as the edge of the ice was discernible to within 1 pixel accuracy. This uncertainty also reflects the possible variation of the user selected threshold grey level which defined the edge of the ice. In general, there was a range of threshold intensities which would represent the same edge.

Taking the total derivative of Equation (2) yields Equation (7) which represents the uncertainty of the scale factor, $d S$. The partial derivative terms, or sensitivity coefficients, are shown in Equations (8) and (9). For the example shown in Figure 10 (November 2010 data), the uncertainty of $d S$ becomes 0.093 pixels per $\mathrm{mm}$ where $l_{p}=987 \pm 7$ pixels and $l_{a}=2.987 \pm 0.05 \mathrm{~mm}$ (the uncertainty in the cover width). The uncertainty in $l_{p}$ comes from inspecting Figure 10 where $l_{p, \max }-l_{p}=7$ pixels (or similarly $l_{p}-l_{p, \min }=7$ pixels). For the example shown in Figure 11 (March 2011 data), the uncertainty of $d S= \pm 0.035$ pixels per mm where $l_{p}=631 \pm 2$ pixels (in this case 1 pixel for each side of the line measurement) and $l_{a}=66.56 \pm 0.13 \mathrm{~mm}$ (which was described above).

$$
\begin{gathered}
d S=\left(\left[\frac{\partial S}{\partial l_{a}} d l_{a}\right]^{2}+\left[\frac{\partial S}{\partial l_{p}} d l_{p}\right]^{2}\right)^{1 / 2} \\
\frac{\partial S}{\partial l_{a}}=-\frac{l_{p}}{l_{a}^{2}} \\
\frac{\partial S}{\partial l_{p}}=-\frac{1}{l_{a}}
\end{gathered}
$$

The uncertainty in the angle $\alpha$ is estimated at $\pm 0.2^{\circ}$ due to angle markings on the wall of the windtunnel facility that allow precise positioning of the airfoil relative to the horizontal. As discussed previously, the uncertainty estimate in the angle $\beta$ was estimated to be $\pm 10^{\circ}$ for the November 2010 tests and $\pm 3^{\circ}$ for the March 2011 tests.

The parameters and their uncertainties for the November 2010 and March 2011 test entries are summarized in Table 1. Using these parameters, the overall uncertainty in the leading edge ice thickness, $G$, as a function of the ice thickness itself is shown in Figure 13. In the November 2010 case, the uncertainty grows as a function of thickness beginning at $0.16 \mathrm{~mm}$, which is the minimum resolution of the measurement, and increasing to over $\pm 0.83 \mathrm{~mm}$ at ice growths of $16 \mathrm{~mm}$ ( $\sim 200$ pixels), or just over 5 percent. In the March 2011 case, the uncertainty remains relatively uniform at just over $\pm 0.21 \mathrm{~mm}$ with only a very slight increase at larger thicknesses. The growing uncertainty in the November 2010 data is attributable to the large uncertainty in the angle $\beta$. This can be seen by the fraction of the overall uncertainty attributable to angle $\beta$ as defined in Equation (10). Equations (11) to (13) show the fractions of the uncertainties for the remaining parameters related to the ice thickness measurement $G_{p i x}$, $\alpha$, and $\beta$, respectively. In the March 2011 data, the major factor contributing to the uncertainty is the pixel resolution, $\mathrm{d} G_{p i x}$, with the scale factor $\mathrm{S}$ uncertainty, $d S$, beginning to have a non-negligible uncertainty at large ice thicknesses as can be seen in Figure 13.

$$
d G_{\beta}=\frac{\left[\frac{\partial G}{\partial \beta} d \beta\right]^{2}}{(d G)^{2}} d G
$$




$$
\begin{gathered}
d G_{G_{p i x}}=\frac{\left[\frac{\partial G}{\partial G_{p i x}} d G_{p i x}\right]^{2}}{(d G)^{2}} d G \\
d G_{S}=\frac{\left[\frac{\partial G}{\partial S} d S\right]^{2}}{(d G)^{2}} d G \\
d G_{\alpha}=\frac{\left[\frac{\partial G}{\partial \alpha} d \alpha\right]^{2}}{(d G)^{2}} d G
\end{gathered}
$$

TABLE 1.-PARAMETERS AND UNCERTAINTIES USED TO MEASURE THE LEADING-EDGE ICE GROWTH FROM VIDEO IMAGES

\begin{tabular}{|c|c|c|c|c|}
\hline Parameter & Date & Case & Value & Uncertainty \\
\hline \multirow{2}{*}{$G_{p i x}$} & November 2010 & All & 0 to 200 pixels & \pm 2 pixels \\
\cline { 2 - 5 } & March 2011 & All & 0 to 200 pixels & \pm 2 pixels \\
\hline \multirow{3}{*}{$S$} & November 2010 & 144 & $13.003 \frac{\text { pixels }}{\mathrm{mm}}$ & $\pm 0.093 \frac{\text { pixels }}{\mathrm{mm}}$ \\
\cline { 2 - 5 } & March 2011 & March 8 & $9.480 \frac{\text { pixels }}{\mathrm{mm}}$ & $\pm 0.035 \frac{\text { pixels }}{\mathrm{mm}}$ \\
\hline \multirow{2}{*}{$\alpha$} & November 2010 & All & 0 or $6^{\circ}$ & $\pm 0.2^{\circ}$ \\
\cline { 2 - 5 } & March 2011 & All & 0 or $6^{\circ}$ & $\pm 0.2^{\circ}$ \\
\hline \multirow{2}{*}{$\beta$} & November 2010 & All & $+10^{\circ}$ & $\pm 10^{\circ}$ \\
\cline { 2 - 5 } & March 2011 & All & $-6^{\circ}$ & $\pm 3^{\circ}$ \\
\hline
\end{tabular}
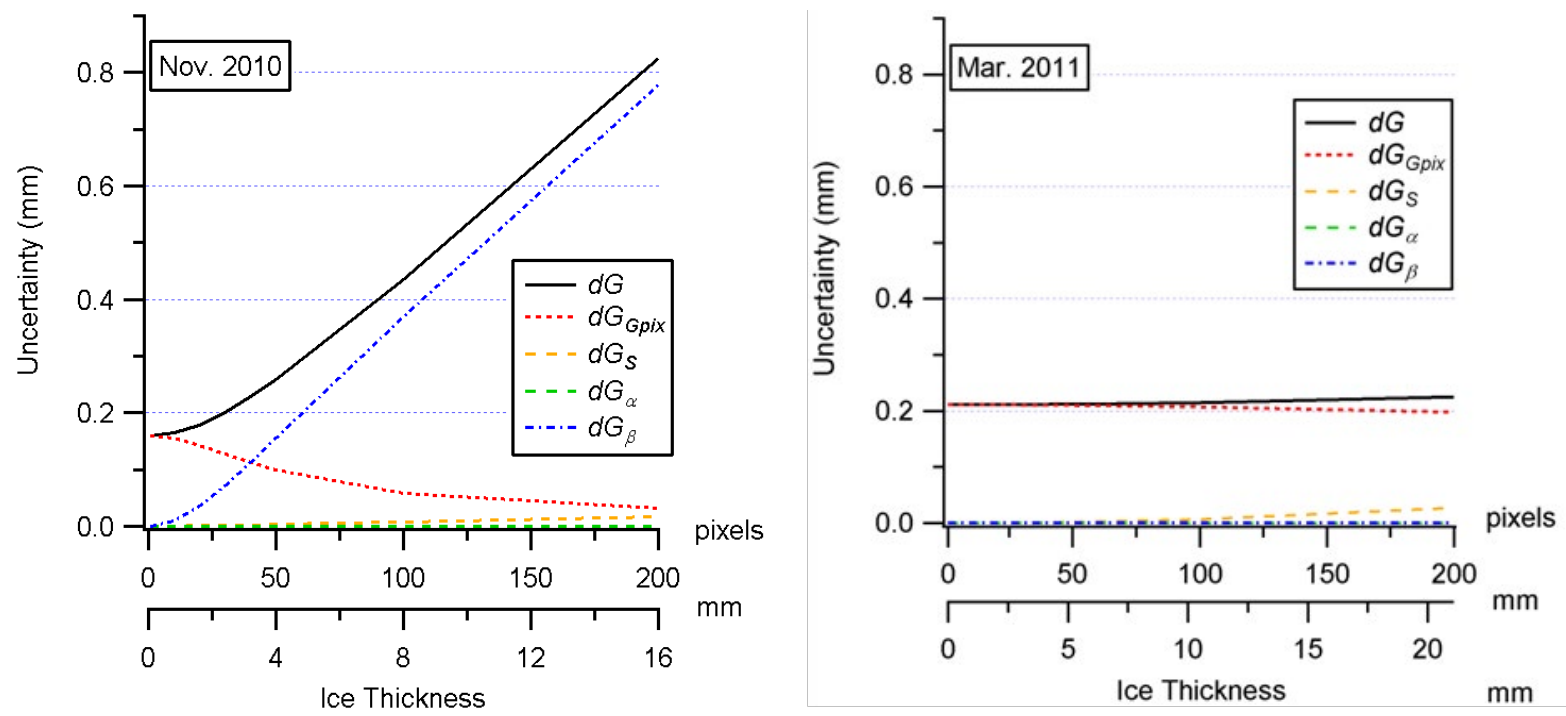

Figure 13.-Uncertainty estimate for the ice thickness measurement during the November 2010 and March 2011 test entries. 
The leading-edge ice thickness data are used to estimate the growth rate which has been observed to be generally linear in several cases as will be discussed in the results. It is useful to understand how the overall bias error on the ice thickness can affect the growth rate, or more specifically, the slope of the ice thickness versus time. If we define the slope of the line, $m$, as seen in Equation (14) starting with some minimum thickness, $G_{\min }$, to some maximum thickness, $G_{\max }$, over a period of time, $t$, then we can create the overall uncertainty for the slope, $d m$, as shown in Equation (15). Again, we use a root-sum-square method to combine the uncertainties of the various parameters based on their sensitivity coefficients shown in Equations (16) to (18). The values for $d G_{\max }$ and $d G_{\min }$ will be the same as the uncertainty for $d G$ at that thickness (see again Figure 13). The uncertainty for the time interval, $d t$, will come from the precision of the timing assuming that the measurement bias is quite small for the time periods being measured. For the HD cameras used in the experiment, the frame rate is $59.94 \mathrm{~Hz}$ where \pm 1 frame corresponds to $\pm 0.0167 \mathrm{~s}$. Since the time intervals required for appreciable ice growth are on the order of minutes, the uncertainty associated with the timing is exceedingly small. The bias uncertainty for a given slope measurement is presented with the data in the results section below.

$$
\begin{gathered}
m=\frac{G_{\max }-G_{\min }}{t} \\
d m=\left(\left[\frac{\partial m}{\partial G_{\max }} d G_{\max }\right]^{2}+\left[\frac{\partial m}{\partial G_{\min }} d G_{\min }\right]^{2}+\left[\frac{\partial m}{\partial t} d t\right]^{2}\right)^{1 / 2} \\
\frac{\partial m}{\partial G_{\max }}=\frac{1}{t} \\
\frac{\partial m}{\partial G_{\min }}=\frac{1}{t} \\
\frac{\partial m}{\partial t}=-\frac{G_{\max }-G_{\min }}{t^{2}}
\end{gathered}
$$

\section{Results}

Results from two cases, one each from the November 2010 and March 2011 test entries, are presented. Figure 15 and Figure 16 show the leading-edge ice growth measurements and analysis for run 144 (November 2010) and run 543 (March 2011), respectively. Both cases had similar, although not identical, conditions which led to significant ice growth over several minutes. In both cases, ice crystals and supplemental water sprays were used. In the figures, the green (water) and blue (ice) dashed lines represent facility parameters which change value from 0 to 1 when the respective flow begins. An abscissa of 0 corresponds to whichever flow, water or ice, came on first. As was typical due to the manual activation, the water and ice came on at slightly different times which in the case of run 144 and 543 were about $5.5 \mathrm{~s}$ apart for both cases. The values of the ice and water parameters changed from 1 to 0 when flow was commanded off. For run 144, the water and ice remained on for approximately $400 \mathrm{~s}$. For approximately the last minute of each test run, a Science Engineering Associates multiwire probe was inserted into the flow just upstream of the test article to measure the cloud water content concentrations. This effectively ended the test since ice growth beyond this was affected by the presence of the upstream probe. The multiwire probe was inserted at approximately 298.5 and $197.7 \mathrm{~s}$ after the test began for runs 144 and 543, respectively. 
In Figure 14 (November 2010), the ice begins to develop measurable thickness (red symbols) approximately $15 \mathrm{~s}$ after the water spray is turned on. Thermocouple data presented elsewhere (see Figure 13 in Ref. 1) suggests that the surface temperature needs to reach a near freezing temperature before ice begins to accrete. The ice continually grows and reaches a thickness of $13.04 \pm 0.69 \mathrm{~mm}$ at $298.5 \mathrm{~s}$ after which a multiwire probe is inserted into the test section effectively ending the test. The uncertainty in the ice thickness measurement is estimated using the process described previously and increases with increasing ice thickness as seen by the error bars which are shown every $30 \mathrm{~s}$ in Figure 14. At the end of the test run, the uncertainty is approximately 5.2 percent of the measured thickness. However, earlier in the test when the ice growth was only about $2 \mathrm{~mm}$, the uncertainty was approximately 10 percent of the measurement.

In Figure 14, a linear curve fit of the data between 15.1 and $298.5 \mathrm{~s}$ yields a slope, or growth rate, of $0.0482 \pm 0.0025 \mathrm{~mm} / \mathrm{s}$. In this case, the growth rate was roughly linear after about $60 \mathrm{~s}$ into the test. The uncertainty of the slope, which was about 5 percent, was estimated using the method described previously which accounts for the uncertainty in the ice-thickness measurement. It is important to note that this uncertainty reflects the potential bias error in the measurement and not the run-to-run variation for the same conditions which has yet to be measured.

To keep the leading edge of the ice within the FOV, the camera was zoomed out remotely for run 144. This was done at two primary times as marked in Figure 14 (black vertical hatched lines). The zoom controls on the camera were somewhat coarse requiring minor adjusting to get the desired view - the hatched lines in Figure 14 represent the time when the camera zoom was set to its desired position. Representative images at different camera zooms are shown in Figure 16. The images corresponding to 120 and $240 \mathrm{~s}$ show a spanwise ice profile which is thickest near the edges (airfoil root and tip) with the smallest growth near midspan. After the multiwire probe is inserted at $298.5 \mathrm{~s}$, the ice thickness becomes highly irregular as seen in the image corresponding to $360 \mathrm{~s}$ in Figure 16. In this image, the multiwire probe is not visible but has been inserted from the right as can been seen by referring back to Figure 3 . The ice thickness plot shown in Figure 14 thus required three different scale factors due to the camera zoom change. Initially, the scale factor was $13.003 \pm 0.093$ pixels $/ \mathrm{mm}$. The scale factor changed to $11.032 \pm 0.093$ and $9.202 \pm 0.092$ pixels $/ \mathrm{mm}$ after 215 and $325 \mathrm{~s}$, respectively.

In Figure 14, there are several data points which appear offset above the main set of data points. During the November 2010 tests, the still cameras took images every $5 \mathrm{~s}$ during which a light flashed. The light saturated the video image for a frame causing the analysis routine to detect a false edge which appears as momentary large ice thicknesses which repeated at a 5-s interval. These false ice-thickness measurements did not affect the slope calculations due to the large number of data points available. The erroneous measurements due to a flash were only present during the November 2010 data since the still cameras were removed for subsequent test entries.

In Figure 15, the ice reaches a thickness of $15.49 \pm 0.22 \mathrm{~mm}$ at $197.7 \mathrm{~s}$. A linear curve fit of the data between 4.4 and $197.7 \mathrm{~s}$ yields a slope, or growth rate, of $0.0788 \pm 0.0015 \mathrm{~mm} / \mathrm{s}$. In this case, the growth rate was linear throughout the test. Run 543 (Figure 15) had more water and ice impingement when compared with run 144 (Figure 15) which may explain the larger growth rate. The uncertainty of the slope due to bias errors, estimated to be just under 2 percent, was significantly smaller compared to run 144 (November 2010) because the uncertainty in ice growth thickness was much less for the March 2011 tests. 


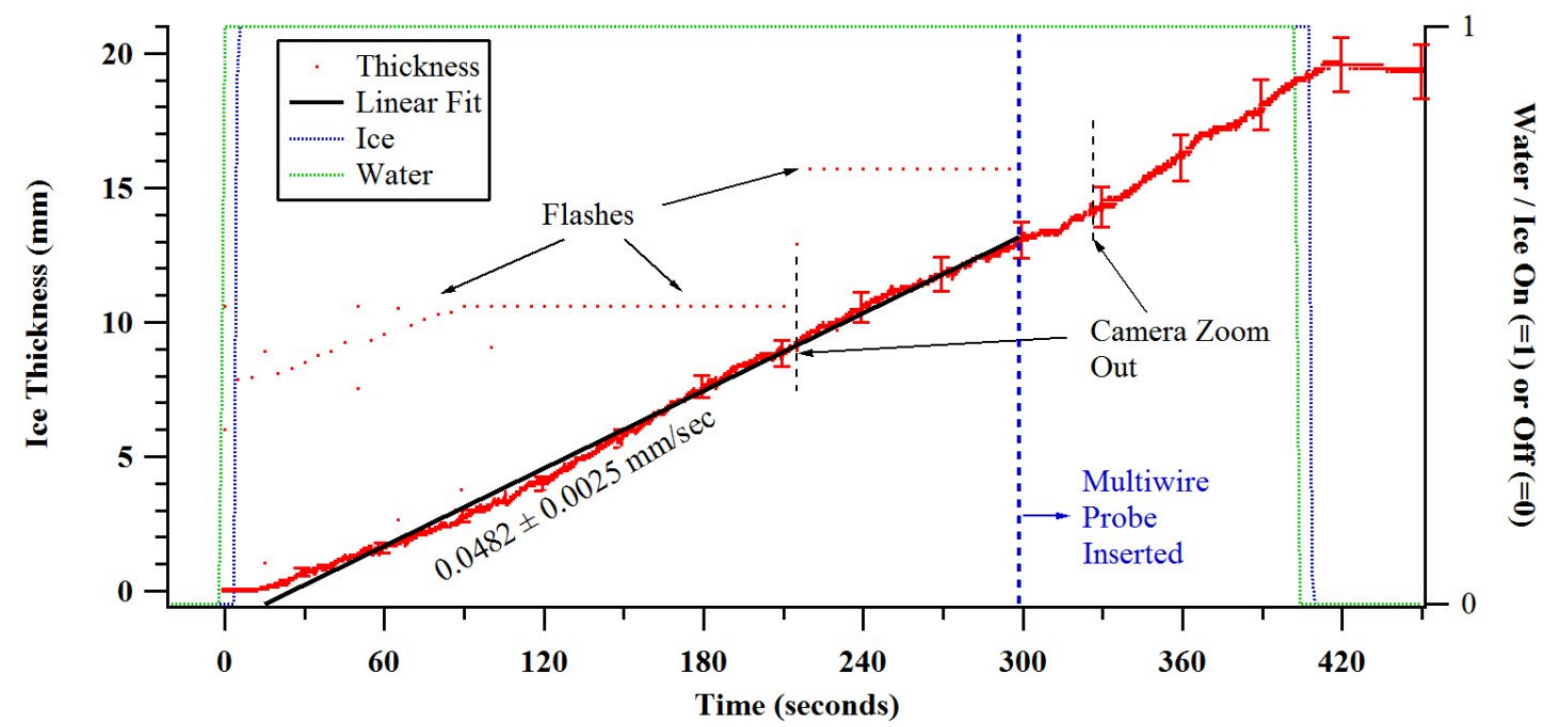

Figure 14.-Leading-edge ice thickness at midspan versus time for run 144 during the November 2010 test entry. The test conditions were $\mathrm{M}=0.20, \mathrm{P}=45 \mathrm{kPa}, \mathrm{TAT}=14.6^{\circ} \mathrm{C}, \mathrm{T}_{\mathrm{WB}}=-1.8^{\circ} \mathrm{C}, \mathrm{IWCi}=5 \mathrm{~g} / \mathrm{m}^{3}$, and $\mathrm{LWCi}=1 \mathrm{~g} / \mathrm{m}^{3}$.

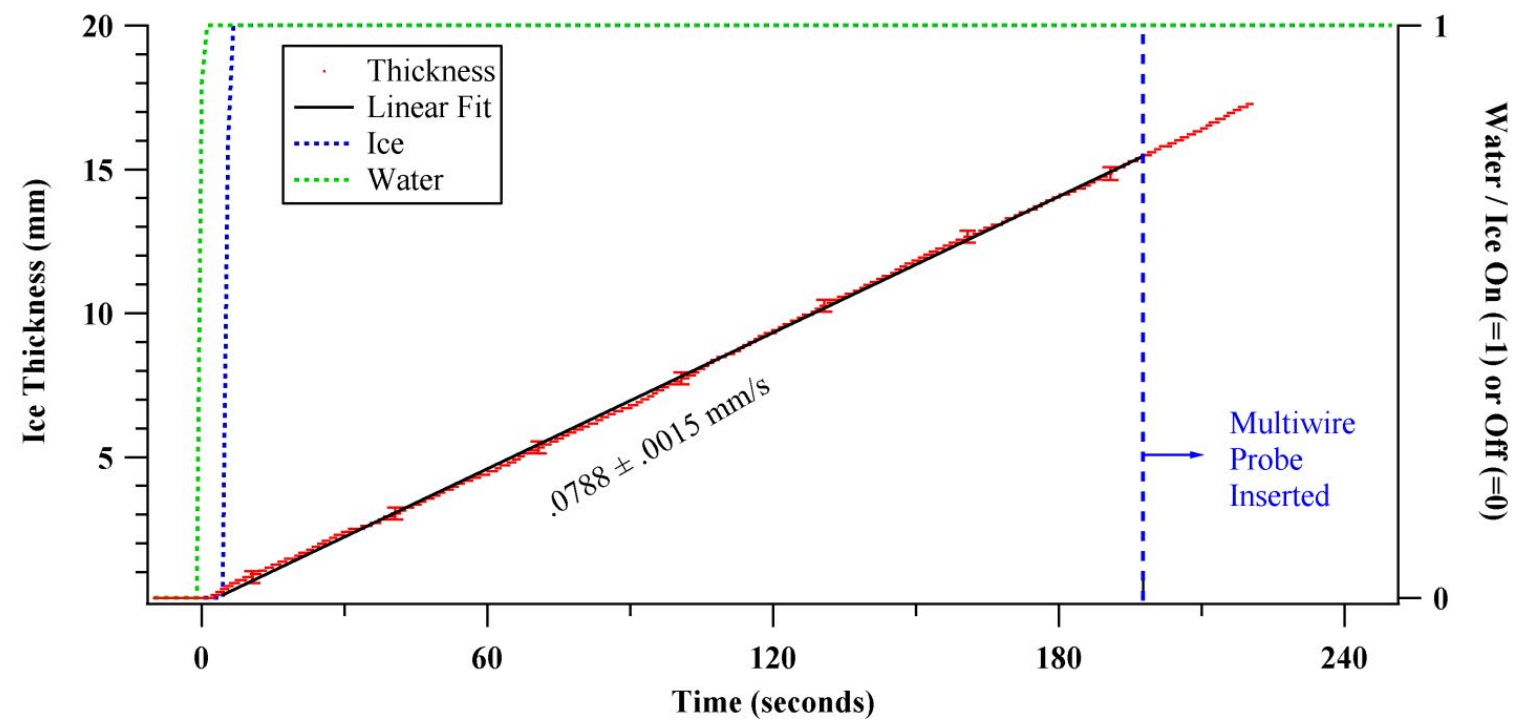

Figure 15.-Leading-edge ice thickness at midspan versus time for run 543 during the March 2010 test entry. The test conditions were $\mathrm{M}=0.25, \mathrm{P}=45 \mathrm{kPa}, \mathrm{TAT}=13^{\circ} \mathrm{C}, \mathrm{TWB}=-2.0^{\circ} \mathrm{C}, \mathrm{IWC}=7 \mathrm{~g} / \mathrm{m}^{3}$, and LWCi $=1.5 \mathrm{~g} / \mathrm{m}^{3}$. 

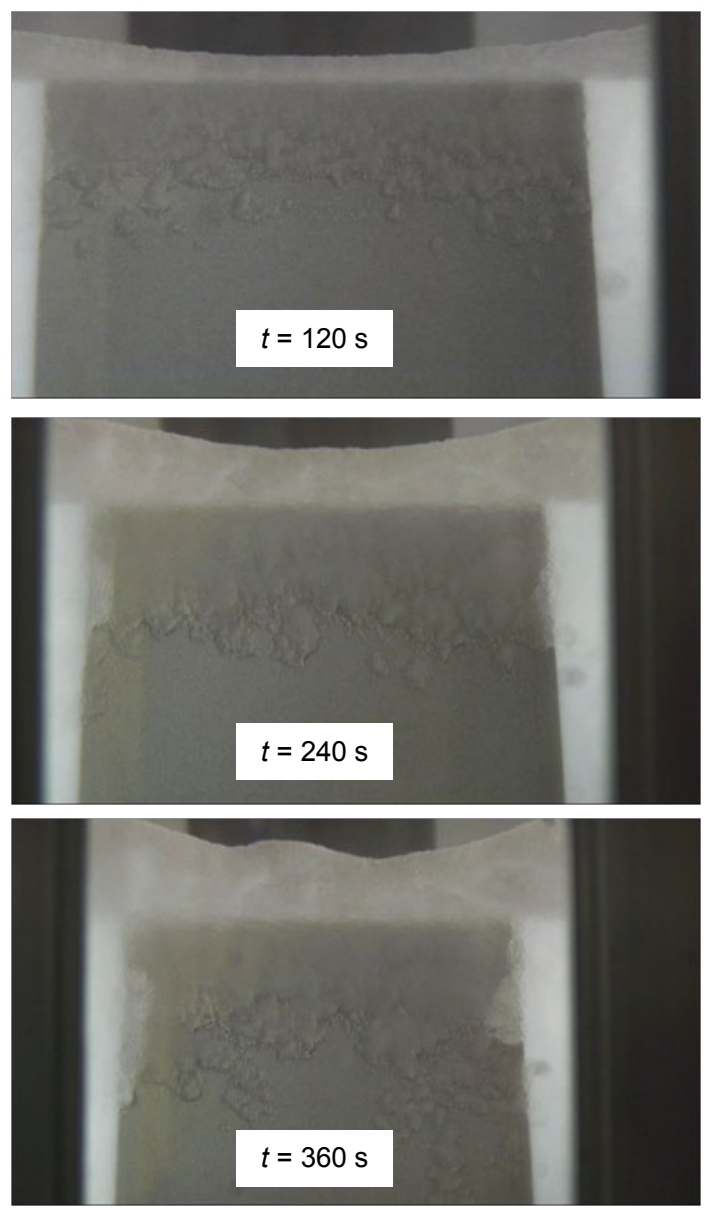

Figure 16.-Select images from run 144 illustrating the different magnification levels required to see the leading edge of the ice.

\section{Discussion}

Two primary changes related to the imaging occurred between the November 2010 and March 2011 tests which have impacted the ice growth analysis: (1) camera orientation and (2) camera zoom. In November 2010, the video camera was considered a secondary view and was intended for real-time feedback in the control room. Due to the larger than anticipated growth rates, the ice grew out of the FOV for several of the still camera images from the top-down view. Fortunately, the HD video camera had a remote zoom capability so that the FOV could be increased. However, the video camera was positioned in an orientation which had a non-normal angle between the imaging plane and ice-growth plane.

Furthermore, this angle was not precisely recorded during testing resulting in a large bias uncertainty of approximately 5 percent of the thickness when the ice growth was large. In the March 2011 tests, the video camera became the primary camera for the top-down view and resulted in a more normal orientation. Despite the slightly larger FOV in March 2011, the measurement uncertainties due to bias were less than 2 percent for similar thickness ice growths.

The off-normal angle between the imaging and ice growth planes caused a perspective effect on the images. Objects at different distances from the imaging plane have different scale factors. For the November 2010 tests, this made the scale factor difficult to interpret since the ice growth grew in a direction that moved away from the imaging plane. The result was greater uncertainty for the measurement of ice thickness (and consequently growth rate) during the November 2010 tests. For the March 2011 tests, the uncertainty was less because there was less uncertainty in the angle between the 
imaging plane and the ice-growth plane. However, the plane in which the maximum ice growth occurs is not always known a priori. In such cases, the approach used for the November 2010 data (i.e., using an average scale factor) may be acceptable provided the associated uncertainty is acceptable.

A major challenge to the ice growth measurement is window obscuration due to water and ice contamination on the windows. This is an inherent issue in the design of the facility which occurs for many test conditions. In cases of contamination, the software algorithm would erroneously detect the ice on the window causing noise in the data. If the ice or water contamination was small and only affected a portion of the window at any given time then the true edge of ice on the airfoil could be detected using multiple ROIs at various spanwise positions on the airfoil. This technique worked well if the ice growth was relatively uniform along the span as the data could be filtered to remove outlying points. This technique also was useful for cases where the ice-growth thickness was not uniform in a spanwise direction thereby requiring multiple measurements across the span. For cases where the image obscuration was too severe, an alternate technique was developed where the ice thickness was measured by seeking the edge of the ice beginning at the airfoil leading edge and looking upstream thereby avoiding upstream flowing ice or water altogether. This technique required the addition of two special ROIs. The first was to mask the airfoil so that pixel grey-level variations on the airfoil itself would not be falsely detected as an edge. The second was a larger area to adjust the original image contrast, which had less contrast locally due to ice or water contamination which resembled the ice growth itself.

Although not described here in detail, illumination of the airfoil with appropriate lighting is a key factor to obtain good contrast during the test. During all of the test entries, light orientations were varied to try and improve image contrast or to accommodate additional cameras. In some cases, the light orientation caused complete obscuration when the cloud was turned on due to the large amount of scattered light into the imager. Unfortunately, these cases were hard to detect before testing as they were a function of tunnel speed and ice and water concentrations. In general, it is good practice to position the lighting to minimize direct back scattering of light into the imager. This could typically be achieved by avoiding coincident lighting and imaging planes.

The transient measurements of leading-edge ice thickness will been useful to compare results from test to test cases especially since the bounds of bias uncertainty have been calculated. Furthermore, the data has offered a new parameter, the growth rate of ice, which to the author's knowledge has not been previously available for icing research. To date, however, it is the only quantitative parameter that has been used to gauge the accretion behavior in the current ice-crystal and mixed-phase research program. Other key parameters, such as the characterization of the two-dimensional and three-dimensional ice shapes as well as surface irregularities (for example, look closely at Figure 16 particularly away from the leading edge at the aft extent of the ice accretion) are required. The additional views captured during the testing could be the focus of future work and have potential to help quantify some of these other key characteristics of ice accretion.

\section{Conclusions}

Experiments studying the fundamentals of ice-crystal icing have gathered video image data showing the ice accretion behavior on a wedge airfoil. Although useful for general observation, the imaging data was intended for quantitative measurements as this represented the only means of recording the icing behavior. As a first step, the ice thickness along the leading edge of the airfoil was measured and presented in this paper. Ultimately, it is desired to be able to extract two-dimensional and threedimensional shapes from the images. Currently, three sets of imaging data are available from testing at the NRC RATFac: (1) November 2010, (2) March 2011, and (3) March and April 2012. Results from the first two test entries were discussed in this paper.

Using the NASA Spotlight software, the ice thickness was measured with an algorithm to detect and record the ice edge as defined by a threshold pixel grey-level value that lies between the bright ice and dark background. Typically, the measurements were made at the airfoil midspan within a user-defined region of interest (ROI). The software algorithm would make the measurement by seeking the ice edge from an upstream to downstream direction. Typically, the image contrast within this ROI was adjusted to 
allow a single threshold grey level to be used across the entire test run during which time the image contrast varied. Other methods were used for cases where the leading edge of the ice was obscured by runback ice and water on the window or if the ice profile was non-uniform across the span.

The original measurements had to be converted from pixels to a physical dimension using a scale factor. The scale factor came from either a known dimension in the image or by placing a scale somewhere in the image. The scale factors were approximately 13.0 and 9.5 pixels per millimeter for the November 2010 and March 2011 tests, respectively. The cameras were zoomed out more for the March 2011 tests allowing a larger FOV due to anticipated larger ice growths. The scale factors varied slightly from test to test due to minor adjustments in camera zoom.

The uncertainty in the ice thickness measurement due to bias, or systematic errors, was estimated for each case and reflects the uncertainty in each of the measured parameters (e.g., raw measurements, scale factors, viewing angles) used to calculate the ice thickness. The reported uncertainty does not account for the random error associated with possible run-to-run variations of the growth rate under the same prescribed environmental conditions. For the November 2010 tests, the minimum uncertainty was approximately $\pm 0.17 \mathrm{~mm}$ and represents the resolution of the measurement. However, the uncertainty increased with ice thickness due to a large uncertainty in viewing angle. For the example presented in this paper, that uncertainly was approximately $\pm 0.83 \mathrm{~mm}$ for an ice thickness of $16 \mathrm{~mm}$. In the March 2011 tests, the uncertainty was primarily due to the measurement resolution, just slightly over $\pm 0.21 \mathrm{~mm}$, and increased only very slightly with thickness. The very slight increase was due to the uncertainty in scale factor which increases with size.

Two cases, one each from the November 2010 and March 2011 test entries, were presented and contrasted. Both cases, which had similar but not identical test conditions, showed significant ice growth with leading-edge thicknesses exceeding 13 and $15 \mathrm{~mm}$, respectively. The growth rates, which could be estimated using a linear curve fit of the data, were $0.0482 \pm 0.0025 \mathrm{~mm} / \mathrm{s}$ for the November 2010 case and $0.0788 \pm 0.0015 \mathrm{~mm} / \mathrm{s}$ for the March 2011 case. The March 2011 case had more water and ice impingement, as well as a larger velocity, all of which may explain the larger growth rate. The uncertainties in the slope reflect the uncertainty due to measurement bias and not the possible run-to-run variation for ice growth which has yet to be measured. The smaller uncertainty in the March 2011 growth rate data is reflective of less bias uncertainty in the ice thickness measurements for those tests.

The transient measurements of leading-edge ice thickness will been useful to compare results from test to test cases especially since the bounds of bias uncertainty have been calculated. Furthermore, the data has offered a new parameter, the growth rate of ice, which to the author's knowledge has not been previously available for icing research.

\section{References}

1. Mason, J. G., Strapp, J. W., and Chow, P. "The Ice Particle Threat to Engines in Flight," 44th AIAA Aerospace Sciences Meeting and Exhibit, AIAA-2006-206, 2006.

2. Struk, P., Currie, T., Wright, W. B., Knezevici, D. C., Fuleki, D., Broeren, A., Vargas, M., and Tsao, J. "Fundamental Ice Crystal Accretion Physics Studies," SAE 2011 International Conference on Aircraft and Engine Icing and Ground Deicing, 2011-38-0018 or NASA/TM-2012-217429, 2011.

3. Knezevici, D. C., Fuleki, D., and MacLeod, J. "Development and Commissioning of the Linear Compressor Cascade Rig for Ice Crystal Research," SAE 2011 International Conference on Aircraft and Engine Icing and Ground Deicing, 2011-38-0079, 2011.

4. Currie, T. C., Struk, P. M., Tsao, J., Fuleki, D., and Knezevici, D. C. "Fundamental Study of MixedPhase Icing, with Application to Ice Crystal Accretion in Aircraft Jet Engines," 4th AIAA Atmospheric and Space Environments Conference, American Institute of Aeronautics and Astronautics, Reston, VA (submitted for publication).

5. Klimek, R., and Wright, T. "Spotlight: Image Analysis and Object Tracking Software." 2005.11.12 ed., NASA Glenn Research Center, Cleveland, OH, 2005.

6. Moffat, R. J. "Describing the Uncertainties in Experimental Results," Experimental Thermal and Fluid Science, Vol. 1, 1988. pp. 3-17. 


\begin{tabular}{|c|c|c|c|c|c|}
\hline \multicolumn{5}{|c|}{ REPORT DOCUMENTATION PAGE } & $\begin{array}{l}\text { Form Approved } \\
\text { OMB No. 0704-0188 }\end{array}$ \\
\hline \multicolumn{6}{|c|}{$\begin{array}{l}\text { The public reporting burden for this collection of information is estimated to average } 1 \text { hour per response, including the time for reviewing instructions, searching existing data sources, gathering and maintaining the } \\
\text { data needed, and completing and revieving the collection of information. Send comments regarding this burden estimate or any other aspect of this collection of information, including suggestions for reducing this } \\
\text { burden, to Department of Defense, Washington Headquarters Services, Directorate for Information Operations and Reports ( } 0704-0188 \text {, } 1215 \text { Jefferson Davis Highway, Suite } 1204, \text { Arlington, VA } 22202-4302 \text {. } \\
\text { Respondents should be aware that notwithstanding any other provision of law, no person shall be subject to any penalty for failing to comply with a collection of information if it does not display a currently valid OME } \\
\text { control number. } \\
\text { PLEASE DO NOT RETURN YOUR FORM TO THE ABOVE ADDRESS. }\end{array}$} \\
\hline \multicolumn{2}{|c|}{$\begin{array}{l}\text { 1. REPORT DATE (DD-MM-YYYY) } \\
01-09-2012\end{array}$} & \multicolumn{3}{|c|}{$\begin{array}{l}\text { 2. REPORT TYPE } \\
\text { Technical Memorandum }\end{array}$} & 3. DATES COVERED (From - To) \\
\hline \multirow{3}{*}{\multicolumn{5}{|c|}{$\begin{array}{l}\text { 4. TITLE AND SUBTITLE } \\
\text { Ice Growth Measurements From Image Data to Support Ice-Crystal and Mixed-Phase } \\
\text { Accretion Testing }\end{array}$}} & 5a. CONTRACT NUMBER \\
\hline & & & & & 5b. GRANT NUMBER \\
\hline & & & & & 5c. PROGRAM ELEMENT NUMBER \\
\hline \multirow{3}{*}{\multicolumn{5}{|c|}{$\begin{array}{l}\text { 6. AUTHOR(S) } \\
\text { Struk, Peter, M.; Lynch, Christopher, J. }\end{array}$}} & 5d. PROJECT NUMBER \\
\hline & & & & & 5e. TASK NUMBER \\
\hline & & & & & $\begin{array}{l}\text { 5f. WORK UNIT NUMBER } \\
\text { WBS 648987.02.02.03.10 }\end{array}$ \\
\hline \multicolumn{5}{|c|}{$\begin{array}{l}\text { 7. PERFORMING ORGANIZATION NAME(S) AND ADDRESS(ES) } \\
\text { National Aeronautics and Space Administration } \\
\text { John H. Glenn Research Center at Lewis Field } \\
\text { Cleveland, Ohio 44135-3191 }\end{array}$} & $\begin{array}{l}\text { 8. PERFORMING ORGANIZATION } \\
\text { REPORT NUMBER } \\
\text { E-18390 }\end{array}$ \\
\hline \multirow{2}{*}{\multicolumn{5}{|c|}{$\begin{array}{l}\text { 9. SPONSORING/MONITORING AGENCY NAME(S) AND ADDRESS(ES) } \\
\text { National Aeronautics and Space Administration } \\
\text { Washington, DC 20546-0001 }\end{array}$}} & $\begin{array}{l}\text { 10. SPONSORING/MONITOR'S } \\
\text { ACRONYM(S) } \\
\text { NASA }\end{array}$ \\
\hline & & & & & $\begin{array}{l}\text { 11. SPONSORING/MONITORING } \\
\text { REPORT NUMBER } \\
\text { NASA/TM-2012-217703 }\end{array}$ \\
\hline \multicolumn{6}{|c|}{$\begin{array}{l}\text { 12. DISTRIBUTION/AVAILABILITY STATEMENT } \\
\text { Unclassified-Unlimited } \\
\text { Subject Category: } 03 \\
\text { Available electronically at http://www.sti.nasa.gov } \\
\text { This publication is available from the NASA Center for AeroSpace Information, 443-757-5802 }\end{array}$} \\
\hline \multicolumn{6}{|c|}{ 13. SUPPLEMENTARY NOTES } \\
\hline \multicolumn{6}{|c|}{$\begin{array}{l}\text { 14. ABSTRACT } \\
\text { This paper describes the imaging techniques as well as the analysis methods used to measure the ice thickness and growth rate in support of } \\
\text { ice-crystal icing tests performed at the National Research Council of Canada (NRC) Research Altitude Test Facility (RATFac). A detailed } \\
\text { description of the camera setup, which involves both still and video cameras, as well as the analysis methods using the NASA Spotlight } \\
\text { software, are presented. Two cases, one from two different test entries, showing significant ice growth are analyzed in detail describing the } \\
\text { ice thickness and growth rate which is generally linear. Estimates of the bias uncertainty are presented for all measurements. Finally some of } \\
\text { the challenges related to the imaging and analysis methods are discussed as well as methods used to overcome them. }\end{array}$} \\
\hline \multicolumn{6}{|c|}{$\begin{array}{l}\text { 15. SUBJECT TERMS } \\
\text { Icing; Engine icing }\end{array}$} \\
\hline \multicolumn{3}{|c|}{ 16. SECURITY CLASSIFICATION OF: } & $\begin{array}{l}\text { 17. LIMITATION OF } \\
\text { ABSTRACT }\end{array}$ & $\begin{array}{l}\text { 18. NUMBER } \\
\text { OF }\end{array}$ & $\begin{array}{l}\text { 19a. NAME OF RESPONSIBLE PERSON } \\
\text { STI Help Desk (email:help@sti.nasa.gov) }\end{array}$ \\
\hline $\begin{array}{l}\text { a. REPORT } \\
\text { U }\end{array}$ & $\begin{array}{l}\text { b. ABSTRACT } \\
\text { U }\end{array}$ & $\begin{array}{l}\text { c. THIS } \\
\text { PAGE } \\
\text { U }\end{array}$ & UU & $\begin{array}{c}\text { PAGES } \\
28\end{array}$ & $\begin{array}{l}\text { 19b. TELEPHONE NUMBER (include area code) } \\
443-757-5802\end{array}$ \\
\hline
\end{tabular}



